\title{
The Influence of Horizontal Environmental Variability on Numerically Simulated Convective Storms. Part I: Variations in Vertical Shear
}

\author{
Yvette P. Richardson* and Kelvin K. Droegemeier \\ School of Meteorology, and Center for Analysis and Prediction of Storms, University of Oklahoma, Norman, Oklahoma \\ ROBERT P. DAVIES-JONES \\ National Severe Storms Laboratory, Norman, Oklahoma
}

(Manuscript received 3 April 2006, in final form 21 December 2006)

\begin{abstract}
Severe convective storms are typically simulated using either an idealized, horizontally homogeneous environment (i.e., single sounding) or an inhomogeneous environment constructed using numerous types of observations. Representing opposite ends of the spectrum, the former allows for the study of storm dynamics without the complicating effects of either land surface or atmospheric variability, though arguably at the expense of physical realism, while the latter is especially useful for prediction and data sensitivity studies, though because of its physical completeness, determination of cause can be extremely difficult. In this study, the gap between these two extremes is bridged by specifying horizontal variations in environmental vertical shear in an idealized, controlled manner so that their influence on storm morphology can be readily diagnosed. Simulations are performed using the Advanced Regional Prediction System (ARPS), though with significant modification to accommodate the analytically specified environmental fields. Several steady-state environments are constructed herein that retain a good degree of physical realism while permitting clear interpretation of cause and effect. These experiments are compared to counterpart control simulations in homogeneous environments constructed using single wind profiles from selected locations within the inhomogeneous environment domain. Simulations in which steady-state vertical shear varies spatially are presented for different shear regimes (storm types). A gradient of weak shear across the storm system leads to preferred cell development on the flank with greater shear. In a stronger shear regime (i.e., in the borderline multicell/supercell regime), however, cell development is enhanced on the weaker shear flank while cell organization is enhanced on the strong shear side. When an entire storm system moves from weak to strong shear, changes in cell structure are influenced by local mesoscale forcing associated with the cold pool. In this particular experiment, cells near the leading edge of the cold pool, where gust front convergence occurs along a continuous line, evolve into a bow-echo structure as the shear increases. In contrast, simulated cells that remain relatively isolated on the flank of the cold pool tend to develop supercellular characteristics.
\end{abstract}

\section{Introduction}

Convective clouds and storms represent one of the most important and challenging problems for forecasters. For this reason, considerable effort has been devoted to studying storm initiation and evolution, as well

\footnotetext{
* Current affiliation: Department of Meteorology, The Pennsylvania State University, University Park, Pennsylvania.

Corresponding author address: Dr. Yvette P. Richardson, Department of Meteorology, The Pennsylvania State University, 503 Walker Building, University Park, PA 16802.

E-mail: yrichardson@psu.edu
}

as the environmental factors governing overall storm structure. Observations (e.g., Marwitz 1972a,b,c; Rasmussen and Blanchard 1998; Evans and Doswell 2001; Markowski et al. 2003) as well as theoretical studies (e.g., Moncrieff and Green 1972; Davies-Jones 1984; Lilly 1986a,b; Rotunno et al. 1988) and numerical simulations (e.g., Klemp and Wilhelmson 1978a,b; Weisman and Klemp 1982, hereafter WK82;Weisman and Klemp 1984; McCaul and Weisman 2001) suggest a relationship between storm type and the vertical buoyancy and shear profiles of the environment. However, nearly all studies consider storms in horizontally homogeneous environments while observed environments can contain significant inhomogeneity.

DOI: 10.1175/MWR3463.1

(C) 2007 American Meteorological Society 
For example, certain aspects of storm behavior have been addressed using theoretical analyses that generally assume an isolated, symmetric updraft in an unchanging and horizontally homogeneous, inviscid, and Boussinesq environment (e.g., Davies-Jones 1984; Lilly 1986a,b). These studies are useful primarily for determining the origin of rotation in severe thunderstorms and, therefore, generally concentrate on supercells. However, they do not provide an understanding of how storms behave when moving through a spatially varying environment.

In the first large parameter space numerical modeling study, WK82 quantified the relationship between storm type and the environment using the Klemp-Wilhelmson model to examine over 80 combinations of buoyancy and unidirectional vertical shear. Both the buoyancy and the vertical shear were horizontally uniform.

WK82 found storm structure to be separated into two distinct modes: secondary redevelopment similar to multicells, and splitting supercells. Both were found to depend upon the bulk Richardson number (BRN) of the environment, defined by

$$
\mathrm{BRN}=\frac{\text { CAPE }}{\frac{1}{2}\left(\bar{u}^{2}+\bar{v}^{2}\right)},
$$

where $\bar{u}$ and $\bar{v}$ represent a difference between the density-weighted mean wind taken over the lowest $6 \mathrm{~km}$ of the profile and a representative surface layer $(500 \mathrm{~m})$ wind for each wind component, and CAPE is the traditionally defined convective available potential energy.

The results of WK82 indicated a predominance of split storms (supercells) for BRN $<35$ and a predominance of secondary (multicell) storms for BRN $>50$. With a constant value of CAPE, increased shear was found to decrease the strength of the initial buoyant plume due to increased entrainment but to aid later redevelopments that tended to form in the region where the outflow directly opposed the shear-induced inflow. With significant unidirectional vertical shear, the initial cell was found to split into equal left-moving (anticyclonic) and right-moving (cyclonic) supercells. By combining bulk measures of shear and buoyancy, Weisman and Klemp produced simulations that agreed quite well with observed severe storm behavior. Their results are limited, however, to storms forming in a homogeneous environment, and it is unclear how storms evolve when moving in environments with variable BRN, which is one focus of our present study. For example, if a storm begins in a high BRN environment and develops as a multicell, how will it adjust if it moves into a region of greater shear (lower BRN)? Forecasters recognize and often address this possibility in their outlook statements, but very few conceptual models exist to predict the influence of inhomogeneities on storm dynamics.

Weisman and Klemp (1984) introduced a dynamical distinction between supercells and ordinary cells (of which multicells are composed), such that a supercell is defined by the existence of dynamically induced mesolows and vertical dynamic perturbation pressure gradients to enhance the updraft, as well as significant correlation between vertical velocity and vertical vorticity. If the dynamics governing supercells and ordinary cells are distinctly different, then one might suspect that the two types of cells will have different responses to inhomogeneities in their environment.

In addition to the aforementioned studies of isolated cells, Rotunno et al. (1988) examined the nature of long-lived squall lines and hypothesized that an optimal balance [Rotunno-Klemp-Weisman (RKW) theory] between cold pool strength and low-level shear would result in deeper, stronger lifting along the gust front. Long-lived squall lines were found to have significant low-level shear directed perpendicular to the squall line. A companion paper (Weisman et al. 1988) largely validated this theory through numerical simulation of squall lines in homogeneous environments over a range of CAPE and vertical shear. While the need for optimal balance to maintain a squall line has been debated (e.g., Stensrud et al. 2005; Weisman and Rotunno 2004, 2005), it is clear that the wind profile ahead of a cold pool does influence the cold pool structure and the forcing of vertical motion along it. It is of interest, then, to know how a storm system with a well-developed cold pool will respond to a change in the environmental wind profile as it moves.

Weisman (1993) extended RKW theory to numerically simulated bow echoes, hypothesizing that the development of a rear-inflow jet helps offset the strong circulation of the cold pool to allow deep lifting along the gust front. Thus, for bow echoes, there was not a simple balance between the cold pool strength and the low-level vertical shear. These simulated systems were shown to develop in environments with large CAPE and strong low-level vertical shear, consistent with observations of Johns and Hirt (1987) but somewhat restrictive conditions compared to those observed by Evans and Doswell (2001) who emphasize the strength of the system-relative inflow rather than the low-level vertical shear, or Coniglio and Stensrud (2001) who obtained derechos in less than optimal conditions.

In contrast to these idealized simulations, real-time predictions or diagnostic case studies based on ob- 
served environments do address environmental variability but are limited in their ability to increase our fundamental understanding because of the concomitant variations in important environmental characteristics (e.g., Xue et al. 2003). In addition, prediction models, by necessity, include surface features such as terrain, soil properties, and radiative fluxes. Given the complex, uncontrolled variations in almost every aspect of an observed environment, real-data predictions make virtually impossible the assessment of basic storm responses to environmental variations.

In summary, the literature reveals that meteorological research has moved from simple 3D simulations of isolated storms in horizontally uniform environments (e.g., WK82; Weisman and Klemp 1984; Rotunno and Klemp 1985) to full storm-scale predictions (Droegemeier 1997) and has largely neglected the area inbetween-an area that is essential if the latter are to be properly interpreted. This study, therefore, seeks to bridge this gap in understanding by conducting carefully designed numerical simulations of storms in idealized but horizontally inhomogeneous environments. The simulations are designed to provide clear storm responses to variations in one particular environmental characteristic at a time in order to aid the interpretation of results. The motivation for this study comes from well-documented and ubiquitous observations showing the large environmental variability of key vertical shear measures (e.g., Markowski et al. 1998; Markowski and Richardson 2007). Perusal of daily shear analyses from numerical models suggests that it is often unlikely storm systems will remain in one shear regime over their entire lifetime. For example, shortwave troughs aloft and low-level jets often influence the mesoscale vertical shear pattern. Remarkably, the consequences of moving from one shear regime to another are unknown and virtually unexplored. Temporal changes in vertical shear were examined by Burgess and Curran (1985) who documented the evolution of a line of storms that was overtaken by a strong shortwave and experienced increased vertical shear and helicity as well as destabilization of the environment. In this case, the line of multicells evolved into distinct tornadic supercells because of this change in their environment. It is reasonable to expect that spatial variations in vertical shear, which result in temporal changes in the storm's reference frame, may have a similarly significant influence on storm type.

In Part I of this study, we examine the influence of variations in vertical shear because previous homogeneous-environment studies (e.g., WK82; Weisman and Klemp 1984) have shown that vertical shear has a significant influence on storm morphology. It is reason- able to assume that changes in this quantity over the lifetime of a storm will also be important. [The variations addressed in this study are in the form of constant gradients at the meso- $\alpha$ scale rather than discontinuities (boundaries) at much smaller scales, which have begun to receive more attention in recent years (e.g., Atkins et al. 1999; Kay and Wicker 1998)]. Section 2 gives details of the model used in the simulations, along with modifications designed to accommodate inhomogeneous environments. In section 3, the formulation of the inhomogeneous shear fields is derived. Results for unidirectional winds in a weak shear regime are described in section 4 , while those in a strong shear regime are described in section 5 . In section 6 , we present results for variations in vertical shear along the mean wind (using nonunidirectional environmental winds). Conclusions and recommendations for future research are given in section 7. In Part II of this study, we examine the response of convective storms to environmental variations in low-level moisture.

\section{Numerical model}

\section{a. General features and configuration}

We use the Advanced Regional Prediction System (ARPS), developed by the Center for Analysis and Prediction of Storms (CAPS) at the University of Oklahoma (Xue et al. 1995, 2000, 2001, 2003). Although the ARPS is a full-physics data assimilation and prediction system, it is used here as a three-dimensional, nonhydrostatic cloud model in the spirit of the Klemp and Wilhelmson (1978a) model. All experiments incorporate Kessler warm rain microphysics, and recent results reproducing many of these simulations with ice microphysics (Kron 2004) do not show the sensitivity of the qualitative results to this choice. To avoid spurious cell generation and overproduction of moist absolutely unstable layers (MAULs; Bryan 2005), we use fluxcorrected transport (FCT; Zalesak 1979) for advection of perturbation potential temperature and total water variables (for further discussion see Richardson 1999). We use fourth-order horizontal and second-order vertical advection for momentum, turbulent diffusivities for momentum and heat $\left(K_{m}\right.$ and $\left.K_{h}\right)$, and base-state potential temperature (defined by a prescribed horizontally homogeneous vertical profile). The model is modified to accommodate an inhomogeneous environment by altering the lateral boundary radiation condition, the computational mixing, and the lateral boundary advection. Details of these modifications are described below.

The horizontal grid spacing is $1.5 \mathrm{~km}$ and the vertical spacing is $350 \mathrm{~m}$ throughout the troposphere, with grid 
TABLE 1. Model settings used in simulations.

\begin{tabular}{|c|c|}
\hline Model process & Setting used \\
\hline Grid dimensions & $\begin{aligned} 90 & \times 192 \times 20 \mathrm{~km}^{3} \text { for unidirectional cases } \\
150 & \times 150 \times 20 \mathrm{~km}^{3} \text { for section } 6 \text { small domain } \\
222 & \times 300 \times 20 \mathrm{~km}^{3} \text { for section } 6 \text { large domain }\end{aligned}$ \\
\hline Potential temperature perturbation & 2-K amplitude \\
\hline Horizontal radius & $10 \mathrm{~km}$ \\
\hline Vertical radius & $1.4 \mathrm{~km}$ \\
\hline Height of max & $1.4 \mathrm{~km}$ \\
\hline Terrain & Flat \\
\hline Horizontal resolution & $1500 \mathrm{~m}$ \\
\hline Vertical resolution & $\begin{array}{l}350 \text { from } 0 \text { to } 1900 \mathrm{~m} \\
\text { Stretching based on } z^{3} \text { applied from } 11.9 \text { to } 20 \mathrm{~km} \\
\text { Avg vertical resolution from } 0 \text { to } 20 \mathrm{~km}=450 \mathrm{~m}\end{array}$ \\
\hline Large time step & 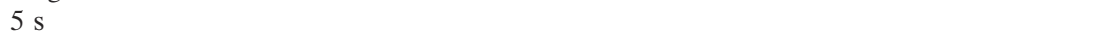 \\
\hline Small time step & $1 \mathrm{~s}$ \\
\hline Lateral boundary conditions & $\begin{array}{l}\text { Radiation condition for normal wind component as in Klemp and Wilhelmson } \\
\text { (1978a; with modifications as described in section } 2 \text { ); phase speed }=45 \mathrm{~m} \mathrm{~s}^{-1} \text {; } \\
\text { relaxation to base state also applied with relaxation coefficient }=0.5\end{array}$ \\
\hline Top boundary condition & Rigid lid with a Rayleigh damping layer from 12 to $20 \mathrm{~km}$ \\
\hline Rayleigh damping coefficient & $0.0067 \mathrm{~s}^{-1}$ \\
\hline Bottom boundary condition & Rigid \\
\hline Surface physics & None \\
\hline Coriolis parameter & 0 \\
\hline Turbulence parameterization & $\begin{array}{l}\text { 1.5-order closure based on predicted TKE, } K_{\mathrm{m}}=0.1 E^{1 / 2} l \text {, where } l \text { is a } \\
\text { stability-dependent length scale following Deardorff }(1980) \text {, and length scales } \\
\text { are assumed to be anisotropic }\end{array}$ \\
\hline Dissipation coef $(\mathrm{Ce})$ & $\begin{array}{l}3.9 \text { at the lowest level } \\
0.93 \text { otherwise }\end{array}$ \\
\hline Computational mixing & $\begin{array}{l}\text { Second order in vertical, coefficient (scaled by vertical grid spacing) }=8.1 \times 10^{-4} \mathrm{~s}^{-1} \\
\text { Fourth order in horizontal, coefficient (scaled by horizontal grid spacing) }=5 \times 10^{-4} \mathrm{~s}^{-1}\end{array}$ \\
\hline $\begin{array}{l}\text { Nondimensional divergence } \\
\text { damping coef }\end{array}$ & 0.05 \\
\hline Nondimensional time filter coef & 0.1 \\
\hline
\end{tabular}

stretching applied in the stratosphere up to a maximum spacing of $1200 \mathrm{~m}$. Although Bryan et al. (2003) suggest using a much finer grid spacing (e.g., $100 \mathrm{~m}$ ) for severe storm simulation in order to correctly represent an inertial subrange, our goal in this study is to examine changes in overall gross storm morphology as storms encounter varying conditions. As such, our grid spacing is believed to be adequate for our goal and was necessary given the large number of simulations in fairly large domains completed over the two-part study. Grid dimensions are $90 \times 192 \times 20 \mathrm{~km}^{3}$ for the unidirectional experiments (sections 4 and 5) and $150 \times 150 \times$ $20 \mathrm{~km}^{3}$ and $222 \times 300 \times 20 \mathrm{~km}^{3}$ for the small and large domains of section 6 , respectively. Simulations are carried out for 3-4.5 h depending on the case.

Storms are initiated at the center of the domain using a thermal perturbation of $2 \mathrm{~K}$ that has a horizontal radius of $10 \mathrm{~km}$ and a vertical radius of $1400 \mathrm{~m}$, along with a moisture perturbation to keep relative humidity equal to the environmental value. The subgrid turbulence closure is a 1.5-order scheme based on turbulent kinetic energy (TKE) with a predicted Prandtl number, an anisotropic, stability-dependent mixing length following Deardorff (1980), and mixing coefficients following Moeng (1984) and Moeng and Wyngaard (1988). No mixing is applied in the normal direction at the boundaries. Details of all model settings are given in Table 1 . A very small asymmetry $(1 \%-2 \%$ error at only a few grid points) develops in this version of the model after several hours but has no noticeable influence on cell intensity, location, or the overall flow pattern over the period of our simulations. For computational efficiency, we exploit flow symmetry and simulate only half of the physical domain in the homogeneous environment control simulations with unidirectional vertical shear. To aid in comparison with the inhomogeneous simulations, the entire physical domain is shown for these half-domain solutions.

\section{b. Modifications to accommodate inhomogeneous environments}

It is perhaps not surprising that little effort has been made to use idealized, inhomogeneous environments 
because cloud-resolving models simply are not designed to accommodate them. For example, waveradiating lateral boundary conditions easily accommodate horizontally homogeneous environments, whereas numerical predictions based on fully 3D observationbased analyses use boundary conditions derived from a larger-scale model (e.g., Droegemeier 1997).

In the present study, inhomogeneous environments are idealized, and incorporation of boundary conditions from a larger-scale model is not possible because many of the environments used to produce reasonable variations across a small domain become absolutely unstable when allowed to extend far past the domain. Thus, significant model alterations are needed to accommodate inhomogeneous, idealized environments. In the discussion that follows, $(u, v)$ refers to the total horizontal wind, $(U, V)$ refers to the total environmental wind, $(\bar{U}, \bar{V})$ refers to the horizontally homogeneous (base state) component of the environmental wind, $\left(U^{\prime}, V^{\prime}\right)$ refers to the perturbation environmental wind with respect to the base state (i.e., $U-\bar{U}, V-\bar{V}$ ), and $\left(u^{\prime}, v^{\prime}\right)$ refers to the departure of the model solution from the environment (i.e., $u-U, v-V$ ). Thus,

$$
\begin{aligned}
u(x, y, z, t) & =\bar{U}(z)+U^{\prime}(x, y, z, t)+u^{\prime}(x, y, z, t) \\
& =U(x, y, z, t)+u^{\prime}(x, y, z, t) \\
v(x, y, z, t) & =\bar{V}(z)+V^{\prime}(x, y, z, t)+v^{\prime}(x, y, z, t) \\
& =V(x, y, z, t)+v^{\prime}(x, y, z, t) .
\end{aligned}
$$

Note that, in this study, the dependence of $U^{\prime}$ and $V^{\prime}$ on time is due only to domain translation.

\section{1) LATERAL BOUNDARY CONDITIONS FOR THE NORMAL VELOCITY COMPONENT}

Most cloud models use some form of open (i.e., radiative) condition for the normal outflowing component of velocity at the lateral boundaries (e.g., Klemp and Wilhelmson 1978a) in order to permit the passage of gravity waves without significantly affecting the interior solution. When the environment itself is inhomogeneous, these lateral boundary conditions treat gradients in the environment as gravity wave disturbances and, thus, attempt to advect any inhomogeneity out through the lateral boundary (Fig. 1a). This eliminates the base-state horizontal gradients in time and also creates artificial regions of convergence and divergence near the edge of the domain, as this effect is greatest at the lateral boundaries. For these reasons, the lateral boundary conditions must be modified when an inhomogeneous environment is used. The solution is to apply a radiative lateral boundary condition only to perturbations from the inhomogeneous base state because these are the modes associated with gravity wave disturbances. The modified lateral boundary condition for an arbitrary variable, $\phi$, at the eastern or western boundary is then

$$
\frac{\partial \phi}{\partial t}-\frac{\partial \phi}{\partial t}_{\mathrm{env}}=-\left(u+c_{x}^{*}\right)\left(\frac{\partial \phi}{\partial x}-\frac{\partial \phi}{\partial x_{\mathrm{env}}}\right) .
$$

Here $\mathbf{c}^{*}=c_{x}^{*} \mathbf{i}+c_{y}^{*} \mathbf{j}$ is an estimated gravity wave velocity set in our simulations to have a speed of $45 \mathrm{~m} \mathrm{~s}^{-1}$ in the direction of the outward normal at each boundary. Equation (4) is applied only to the velocity component normal to the boundary, and only when the phase speed is greater than any inward-directed normal velocity component such that gravity wave propagation would be directed out of the domain (cf. Carpenter 1982). Using this radiative condition, a steady, inhomogeneous environment remains steady in the model and no spurious regions of convergence or divergence develop. An unsteady environment also can be used, as long as the rate of change with time is known.

\section{2) Advection at the lateral boundaries}

When the environment is homogeneous, a zero gradient condition can be assumed for advection when inflow occurs normal to the lateral boundary. In the inhomogeneous case, the advection must be done using the appropriate environmental gradient in order to give the correct time tendency at the boundary (Fig. 1b). Thus, the environmental gradient must be prescribed in some manner. However, simply adding an advection term based on a constant environmental gradient can lead to significant errors if a large perturbation reaches the boundary and the wind changes from outflow to inflow (Fig. 1c). For example, a boundary value that has become greater or less than the environmental value should be expected to return to the environmental value on inflow after some time. The constant gradient condition could, instead, result in further growth of the perturbation in time.

To facilitate the return to environmental values on inflow, a relaxation term is added at the lateral boundary in all simulations. For example, the advection of $u$ by the meridional wind component at the southern boundary on inflow is given by

$$
-{\frac{\partial u}{\partial t_{\mathrm{yadv}}}}=v \frac{\partial U}{\partial y}+r^{*}|v|[u(t-\Delta t)-U(t-\Delta t)] \Delta y^{-1},
$$

where $r^{*}$ is a relaxation coefficient chosen to be 0.5 in our simulations, with the relaxation term lagged in time to maintain linear stability. In the absence of perturba- 


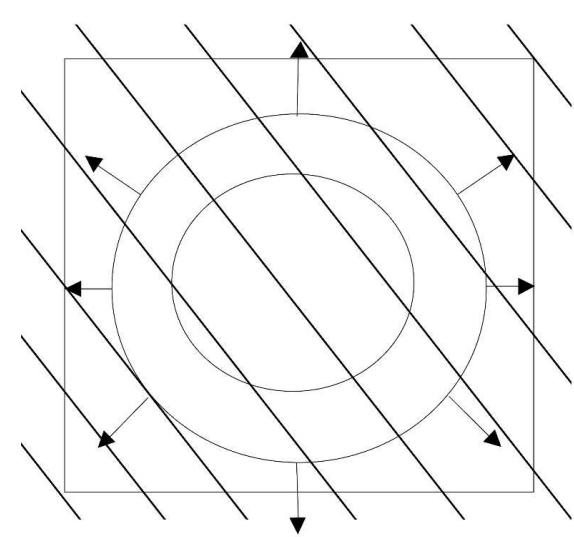

(a)

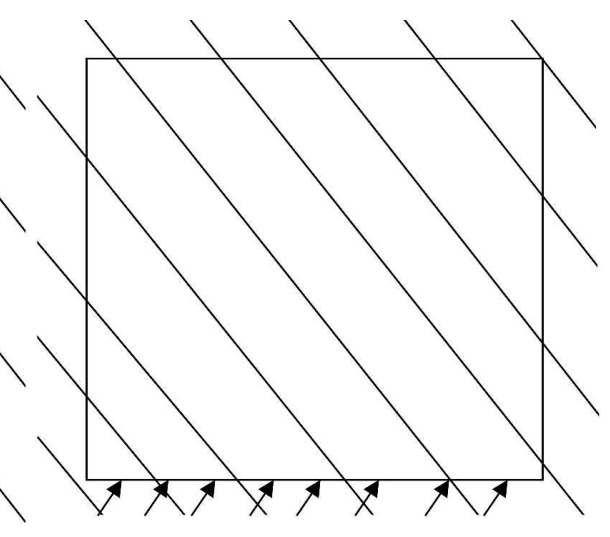

(b)

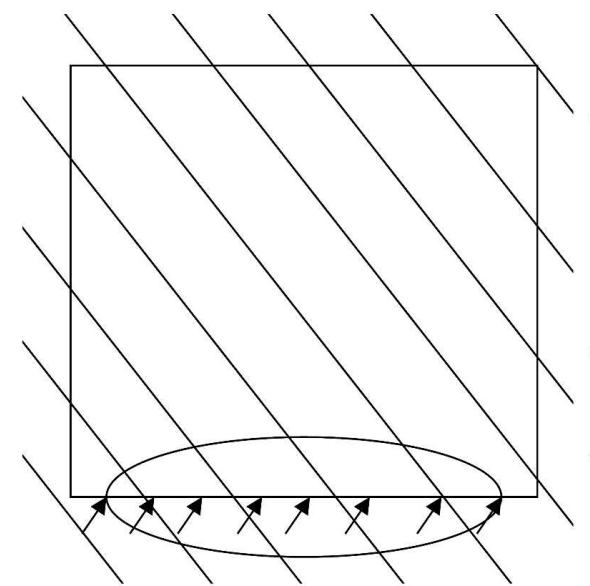

(c)

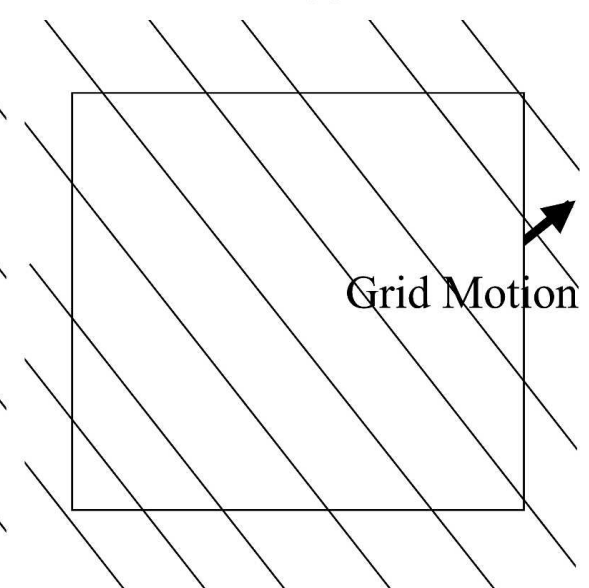

(d)

FIG. 1. Illustrations showing accommodations for an inhomogeneous environment (slanted contours represent those of the environment). (a) A disturbance (circular contours) generated in the interior of the domain must be allowed to pass through the lateral boundaries. (b) Advection of environmental gradients must be included at the lateral boundaries on inflow. (c) A disturbance at the boundary requires a relaxation term to return the boundary value to the environmental value on inflow. (d) Grid translation in an inhomogeneous environment requires extra terms to account for environmental gradients.

tions, the change of $u$ with time due to advection at this southern boundary will be the sum of (5) and the advection of $U$ in the zonal direction. Because the environment is specified to be steady state, the advection terms in the two directions will cancel each other and $u$ will be equal to the environmental value at all times; thus, the relaxation term will have no effect. If, however, disturbances in $u$ and $v$ are present at the lateral boundary, then $u$ will be relaxed back to its environmental value with time as air flows into the domain. This formulation assumes that the advection of the environmental gradient of $u$ by $v^{\prime}=v-V$ is small such that, on pure inflow, $u$ would not depart significantly from its environmental value. Very large environmental gradients, together with very large perturbation $v$ values on inflow, would invalidate this assumption; however, studies suggest that it is justified as long as storms remain sufficiently far from the inflow lateral boundary (Weisman et al. 1998). This specification of lateral boundary conditions is somewhat similar to the procedure used by limited domain models whose boundaries are forced by the solution of a larger-scale model. Due to the inflow assumptions made here, no conclusions about upscale influences, that is, from storm to the larger-scale (i.e., external to the domain) environment, will be made in this study.

\section{3) DOMAIN TRANSLATION}

Domain translation in a homogeneous environment is relatively straightforward, as one simply subtracts the domain speed from the base-state velocity components. When the environment is inhomogeneous, several ad- 


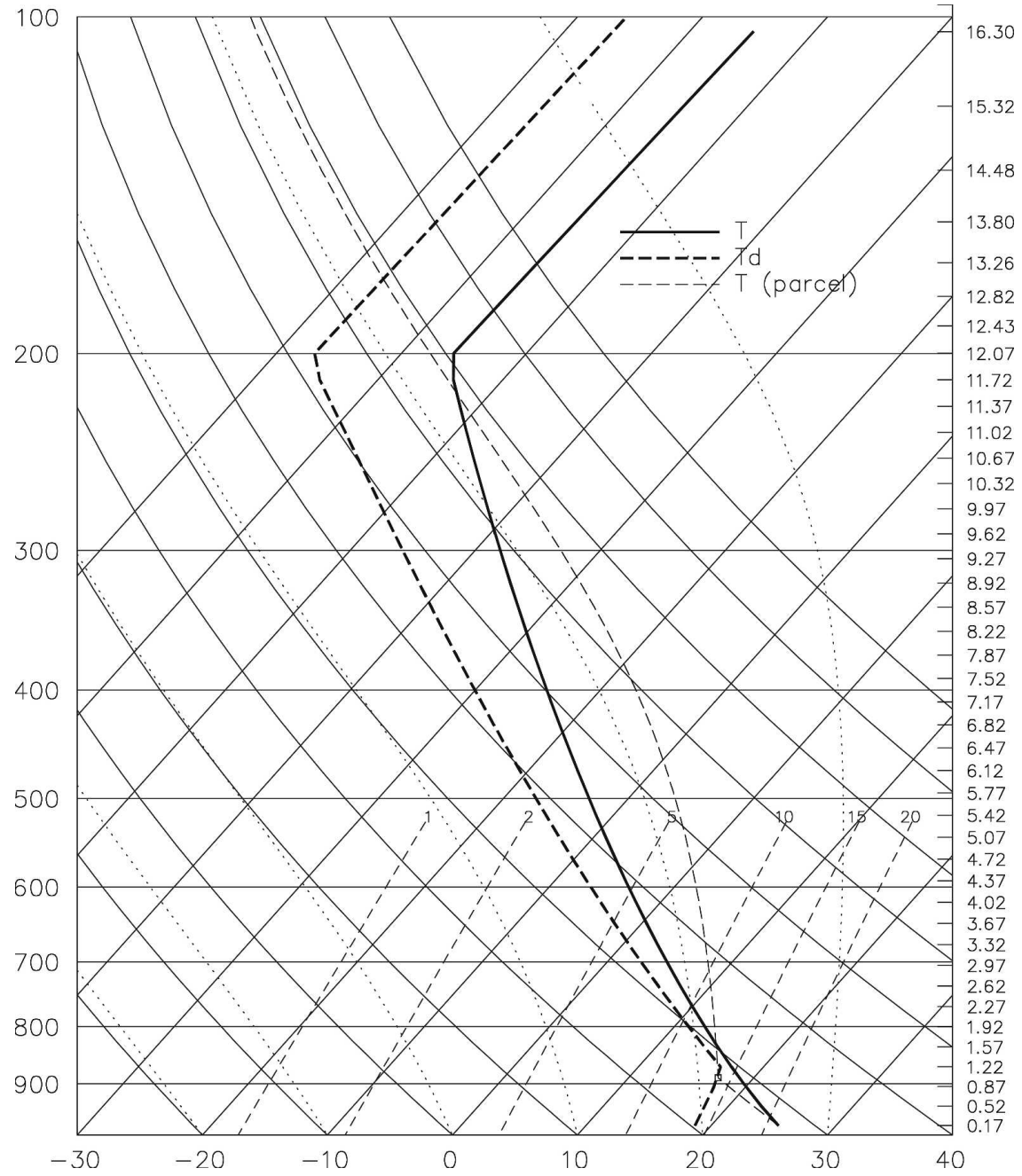

FIG. 2. Skew $T-\log p$ diagram showing temperature and moisture profiles (bold solid and dashed lines) used in simulations. The thin dashed line represents the parcel ascent from the surface. (Based on WK82.)

justments must be made to accommodate the domain translation (Fig. 1d). The grid-relative rate of change of an environmental variable $\phi$ is given by

$$
\frac{\partial \phi}{\partial t}_{\mathrm{env}}=C_{x} \frac{\partial \phi}{\partial x_{\mathrm{env}}}+C_{y} \frac{\partial \phi}{\partial y_{\mathrm{env}}},
$$

where $C_{x}$ and $C_{y}$ are the domain translation speeds in the $x$ and $y$ directions, respectively. The computation of the right-hand side is simplified greatly by making $(\partial \phi /$ $\left.\partial x_{\text {env }}\right)$ and $\left(\partial \phi / \partial y_{\text {env }}\right)$ uniform horizontally, since one is not then required to track the position of the grid in the larger environment to determine these values.

With regard to the normal velocity components, if the environment is steady but the domain moves in time, then $\left(\partial \phi / \partial t_{\text {env }}\right)$ is used in the radiation boundary condition in (4) to specify the change at the lateral boundary due to domain motion. Similarly, arrays defining the background inhomogeneous environment, used in the computational mixing and lateral boundary relaxation routines for all variables, must be adjusted by adding (6) at each time step to account for domain movement through the inhomogeneous environment.

If the domain speed is changed during a simulation, as is often necessary, care must be taken to adjust the $t-\Delta t$, or past time, values of all variables in the leapfrog scheme such that the next time step results in the correct time tendency (i.e., to ensure that the solution remains Galilean invariant), according to

$$
{\frac{\partial \phi}{\partial t_{\text {new }}}}={\frac{\partial \phi}{\partial t_{\text {old }}}}+\Delta C_{x} \frac{\partial \phi}{\partial x}+\Delta C_{y} \frac{\partial \phi}{\partial y},
$$


where $\Delta C_{x}$ and $\Delta C_{y}$ give the changes in the domain motion in the $x$ and $y$ directions, respectively, and $\phi$ represents any model variable. Thus, $\phi$ at time $t-\Delta t$ is adjusted such that

$$
\phi(t-\Delta t)_{\text {new }}=\phi(t-\Delta t)_{\text {old }}-\Delta t\left(\Delta C_{x} \frac{\partial \phi}{\partial x}+\Delta C_{y} \frac{\partial \phi}{\partial y}\right),
$$

where the gradients are evaluated as an average of values at $t$ and $t-\Delta t$. When radiation lateral boundary conditions are used in a homogeneous environment, a zero gradient condition normally is assumed at the boundary when applying (8). In our case, the environmental gradient is used for adjusting the boundary points. Domain translation adjustments must also be applied to the inhomogeneous environmental arrays (valid at $t-\Delta t$ ) used for computational mixing. To evaluate the new boundary formulations and ensure that they do not create any spurious perturbations, simulations were performed with an inhomogeneous base state of vertical shear and no thermal perturbation (i.e., no storm). The inhomogeneous environment remains steady as the domain moves in time and no spurious perturbations are created at the boundaries. The maximum values of vertical velocity, perturbation potential temperature, cloud water, and perturbation pressure are all within computer round-off error.

\section{Formulation of the inhomogeneous environment}

There are many ways in which the vertical environmental shear can vary in both space and time, often as the result of specific observed mesoscale features. In this study, the focus is not on replicating such features using real data, but instead on understanding their influence on storm structure in the context of a realistic, steady-state, spatially varying environment, the configuration of which is specified analytically in order to facilitate control and interpretation. Environments are created for both weak and moderately strong shear, including a case in which the vertical shear varies along the mean wind. In all experiments, thermodynamic properties are homogeneous and characterized by a WK82 profile with a mixed-layer mixing ratio of $14 \mathrm{~g} \mathrm{~kg}^{-1}$ (Fig. 2), corresponding to a CAPE value of approximately $2200 \mathrm{~J} \mathrm{~kg}^{-1}$.

To greatly simplify the specification of steady-state, inhomogeneous environments, the Coriolis force is not included in these simulations. Its exclusion is justifiable for relatively short-lived phenomena (i.e., less than $4 \mathrm{~h}$ ), and in the context of vorticity dynamics, it may be ex-

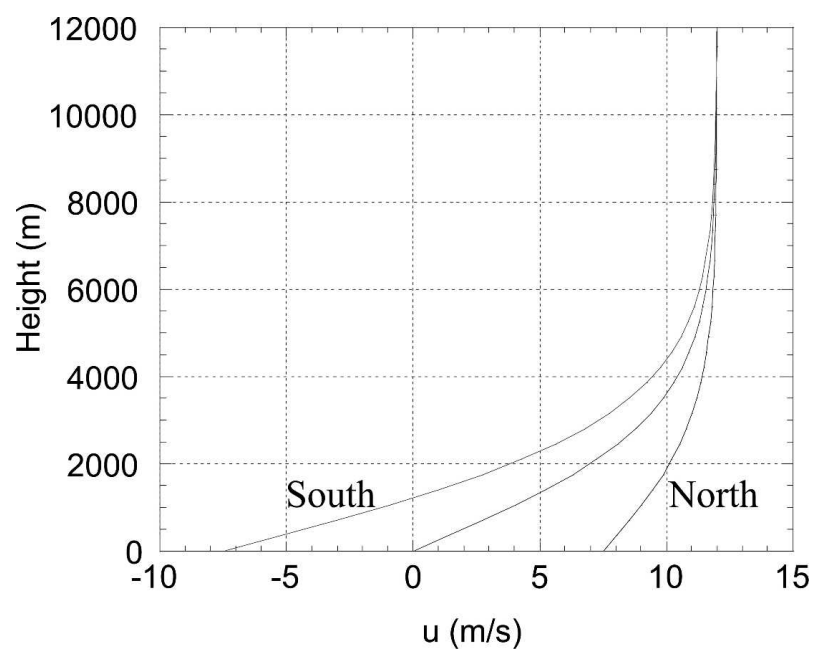

FIG. 3. Profiles of east-west velocity component for inhomogeneous, unidirectional, weak shear experiments. The middle line represents the profile at the domain center, while the other two lines represent profiles at a distance of $75 \mathrm{~km}$ to the north and south of the domain center.

cluded if the tilting term is significantly larger than the stretching term associated with planetary vorticity (Davies-Jones 1984). This will be true if

$$
\left(\frac{\partial w}{\partial z} f\right) /\left(\frac{\partial w}{\partial y} \frac{\partial U}{\partial z}\right) \ll 1
$$

or, using scale analysis,

$$
\frac{f D}{H S} \ll 1,
$$

where $S$ represents the shear of the environment (normally $\partial U / \partial z$ ), $D$ represents the horizontal scale of the storm, and $H$ represents the vertical scale. For a deep convective storm, $D / H=1$, so the Coriolis force may be excluded as long as it is much smaller in magnitude than the environmental shear. In our simulations, this condition is always satisfied and, thus, the Coriolis force is not included. (Note that this simple-scale analysis is not appropriate near the ground where $w=0$ but $\partial w / \partial z \neq$ 0 . Thus, any conclusions made here regarding changes in vorticity close to the ground will be made with caution.)

To devise an environment that remains steady in the absence of planetary vorticity, consider the momentum equations for an inviscid fluid in a nonrotating reference frame, given by

$$
\frac{\partial \mathbf{v}}{\partial t}+\mathbf{v} \cdot \nabla \mathbf{v}=-\frac{1}{\rho} \boldsymbol{\nabla} p-g \mathbf{k}
$$



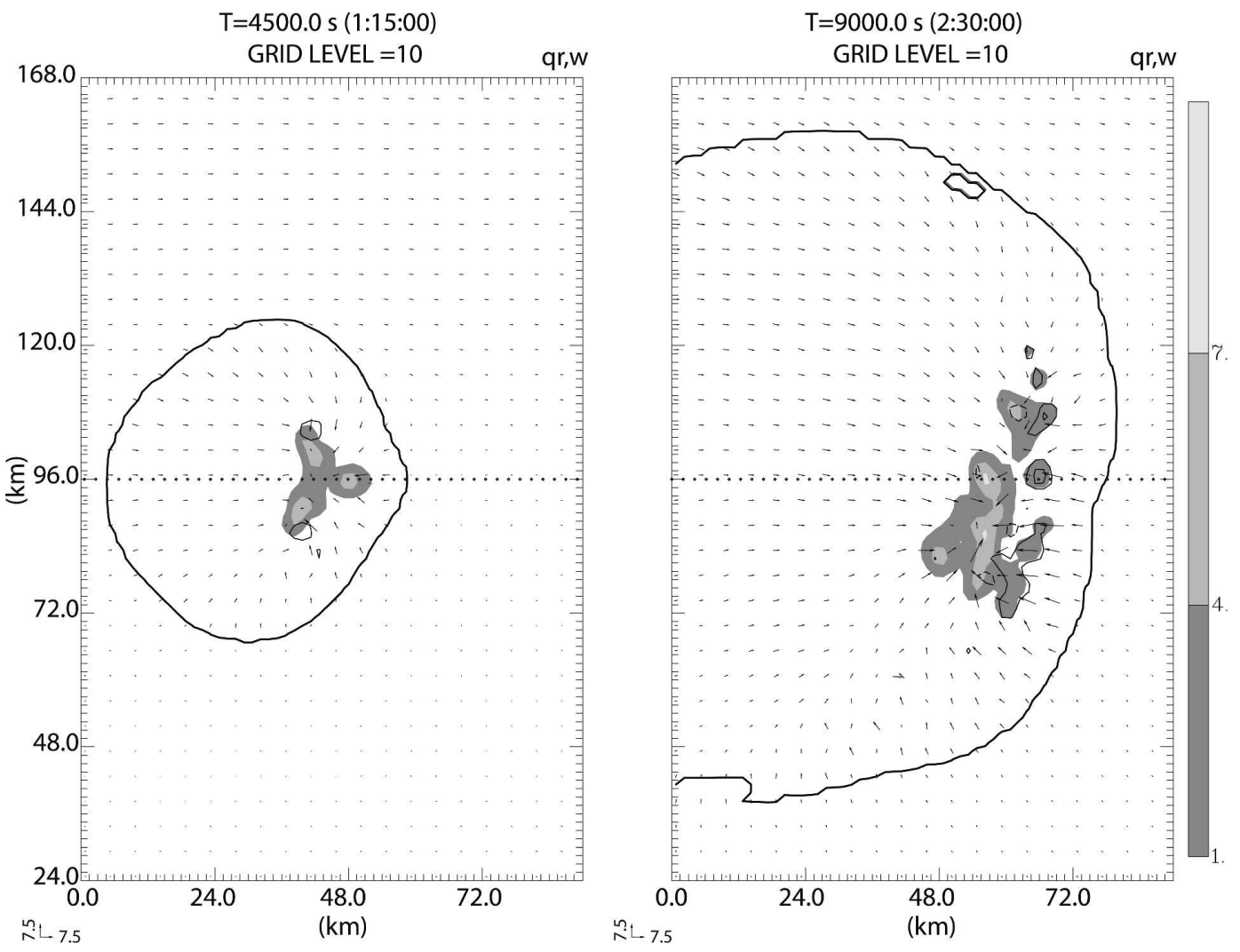

FIG. 4. Horizontal cross section of rainwater mixing ratio $\left(\mathrm{g} \mathrm{kg}^{-1}\right.$, shaded), vertical velocity $\left[5.0 \mathrm{~m} \mathrm{~s}^{-1}\right.$, solid (dashed) for positive (negative) values, thick contours, zero line omitted], and storm-relative winds at grid level 10 $(z=2.975 \mathrm{~km}$ ) at (a) 4500 and (b) $9000 \mathrm{~s}$ for inhomogeneous, unidirectional, weak shear experiments. The bold line indicates the gust front ( $-1 \mathrm{~K}$ perturbation potential temperature at the surface) and the dotted line indicates the symmetry line for a corresponding homogeneous case.

from which it is clear that a hydrostatic environment, with no horizontal pressure gradients, is such a solution provided that the advection terms are zero. The simplest environment satisfying the requisite conditions consists of the superposition of a horizontally homogeneous base-state wind that is unidirectional with height and a perturbation environmental wind that is parallel to it with a magnitude varying in the direction perpendicular to the wind direction. [A configuration somewhat similar to this was used by Skamarock et al. (1994) to study the effect of environmental variability along a squall line. However, both the shear and CAPE varied in their study.] The use of a unidirectional wind provides considerable flexibility in the allowed magnitudes of the perturbations; however, it has the inherent drawback of allowing shear variations only in a direction perpendicular to the mean wind. This prevents storms moving with the mean wind from encountering variations in shear as they move. Nevertheless, simulations using unidirectional shear are presented, and an understanding of them is essential to the understanding of the more complicated environmental configuration that follows.

If winds are not unidirectional with height, then an initial condition producing steady-state horizontal winds may be found in which the shear does vary in the direction of the mean wind over the cloud layer, thus allowing the shear to vary along the storm's motion vector. In the horizontal equations of motion for the environment, the advection terms may be written $J(\psi, U)$ and $J(\psi, V)$ :

$$
J(\psi, U) \equiv \frac{\partial \psi}{\partial x} \frac{\partial U}{\partial y}-\frac{\partial \psi}{\partial y} \frac{\partial U}{\partial x}
$$

where the environmental wind is $\mathbf{V}=(U, V, 0)=$ $[-(\partial \psi / \partial y),(\partial \psi / \partial x), 0]$, and $\psi$ is the streamfunction for a particular level. For a steady, nonrotating $(f=0)$, nondivergent 2D environmental flow without friction and horizontal variations in pressure and density, the advection terms have to vanish. In other words, $U$ and $V$ must be functions of $\psi$ (i.e., constant along the stream- 

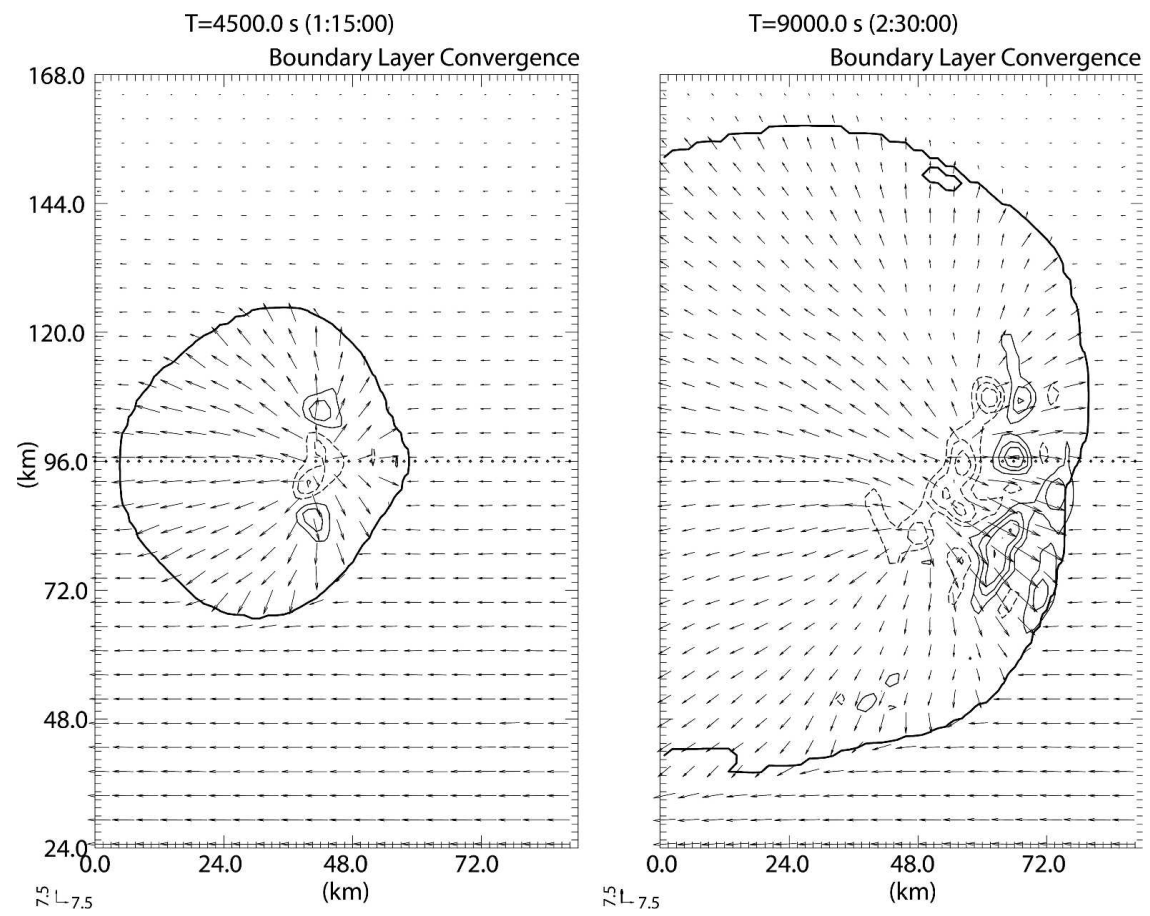

FIG. 5. Horizontal cross section of boundary layer (0-2-km mass weighted) convergence $\left(\mathrm{s}^{-1}\right)$ and storm-relative winds at the lowest grid level at (a) 4500 and (b) $9000 \mathrm{~s}$ for simulation with weak, unidirectional, inhomogeneous shear as in Fig. 3. Boundary layer convergence (BLC) is contoured every $0.5 \mathrm{~s}^{-1}$, with solid (dashed) lines for positive (negative) values, and the zero line is omitted. The bold line indicates the gust front $(-1 \mathrm{~K}$ perturbation potential temperature at the surface) and the dotted line indicates the symmetry line for a corresponding homogeneous case.

lines). Hence, the flow in each level has to have straight streamlines that are inclined to the $x$ axis at an angle $\beta(z)=\tan ^{-1}(V / U)$. There is no restriction on the horizontal shear $(\partial M / \partial n)$ [where $n(z)$ is the principal normal of the streamlines and $M(\psi)=\sqrt{U^{2}+V^{2}}$ is the wind speed]. Since there is no curvature vorticity, $(\partial M /$ $\partial n)=\zeta$, where $\zeta$ is the vertical vorticity. If we assume linear horizontal variations of the winds, $\zeta$ is a function only of $z$, and the environmental wind is given by

$\left(\begin{array}{l}U \\ V\end{array}\right)=\left(\begin{array}{l}\bar{U} \\ \bar{V}\end{array}\right)+\zeta\left[\left(x-x_{o}\right) \sin \beta-\left(y-y_{o}\right) \cos \beta\right]\left(\begin{array}{c}\cos \beta \\ \sin \beta\end{array}\right)$,

where $\left(x_{o}, y_{o}\right)$ is the point where the hodograph is the base-state hodograph. We can construct hodographs that vary in length and shape across the domain by specifying $\beta, \zeta, \bar{U}$, and $\bar{V}=\bar{U} \tan \beta$ as functions of height. The following constraints guided our search by trial and error for suitable functions: 1) Horizontal shear should be large at the ground to ensure large variation in low-level shear; 2) hodographs should be realistic across the whole domain and should not have undesirable unstable jet structures anywhere; 3 ) vertical shears in any part of the domain should not be so large that the environment becomes dynamically unstable (i.e., the Richardson number becomes less than its critical value);4) the storm system should move in an appropriate direction with sufficient speed so that it encounters significantly different magnitudes and/or types of shear in $4 \mathrm{~h}$. In the first two experiments, the shear is unidirectional $(\beta=0)$ with

$$
\begin{aligned}
\bar{U}(z) & =\bar{U}_{s} \tanh \left(z / z_{s}\right), \quad \bar{V}=0, \\
\zeta(z) & =-10^{-4}\left[1-\tanh \left(z / z_{s}\right)\right] \quad \mathrm{s}^{-1},
\end{aligned}
$$

where $z_{s}=3000 \mathrm{~m}, \bar{U}_{s}=12 \mathrm{~m} \mathrm{~s}^{-1}$ (weak-shear case) or $\bar{U}_{s}=22 \mathrm{~m} \mathrm{~s}^{-1}$ (moderate-shear case), and $\left(x_{o}, y_{o}\right)$ are at the center of the domain. (These wind profiles are shown in the following two sections.) In the third experiment, where vertical shear is designed to have some variation along the direction of the mean wind, the base-state hodograph, which applies at $\left(x_{o}, y_{o}\right)=(300$, 300) $\mathrm{km}$ in a theoretical physical domain that is 

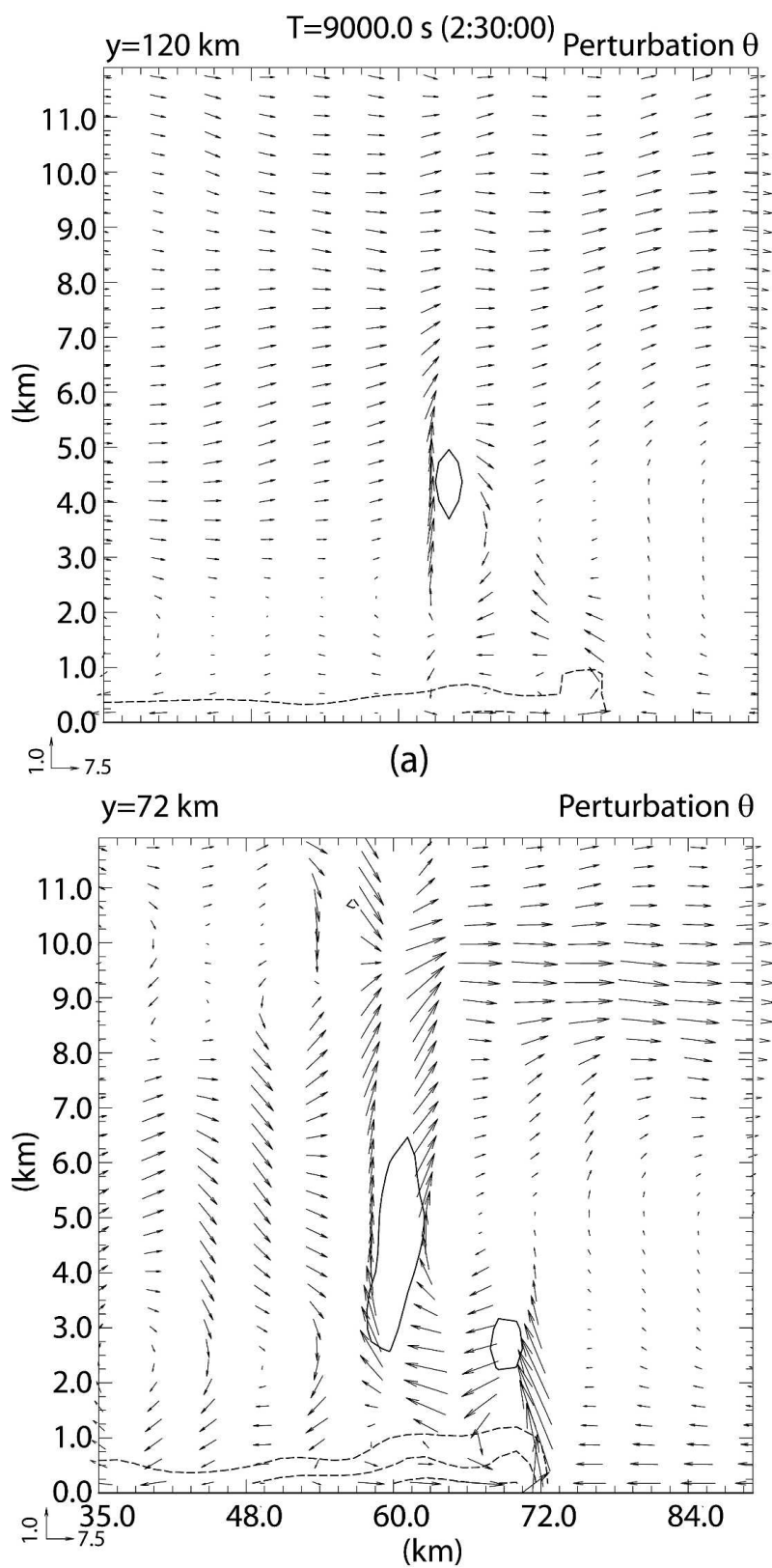

(b)

FIG. 6. Potential temperature perturbation (contoured every $2 \mathrm{~K}$ ) and storm-relative winds at (a) $y=120 \mathrm{~km}$ and (b) $y=72 \mathrm{~km}$ for simulation with weak, unidirectional, inhomogeneous shear as in Fig. 3. Solid lines are positive values, dashed lines are negative values, and the zero line is omitted.

much larger than the actual computational domain (see section 6), is

$$
\begin{aligned}
& \bar{U}(z)=\left[18 \tanh \left(z / z_{s}\right)+5\right] \mathrm{m} \mathrm{s}^{-1}, \\
& \bar{V}(z)=\bar{U}(z)+6 \mathrm{~m} \mathrm{~s}^{-1} .
\end{aligned}
$$

To accommodate the four wind profile goals outlined above, the form of the vertical vorticity is chosen care-

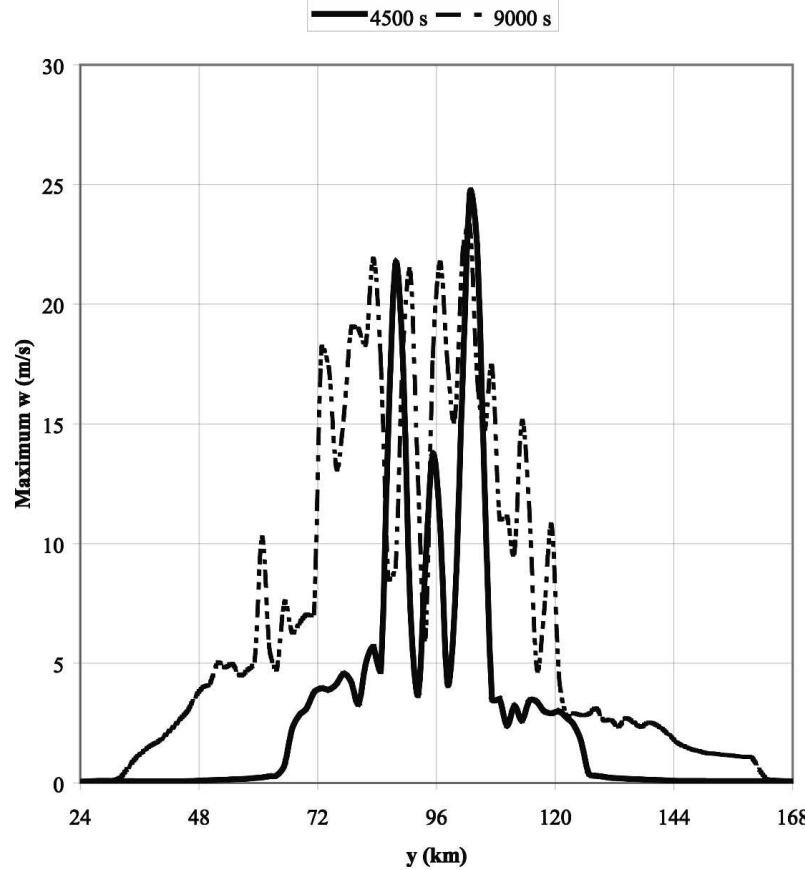

FIG. 7. Maximum vertical velocity vs $y$ at 4500 (bold) and $9000 \mathrm{~s}$ (dash-dot) for simulation with weak, unidirectional, inhomogeneous shear as in Fig. 3.

fully by specifying the desired rate of change of one velocity component along a line and then solving "backward" for the necessary $\zeta$ profile. The desired change in wind profile only can be specified for one of

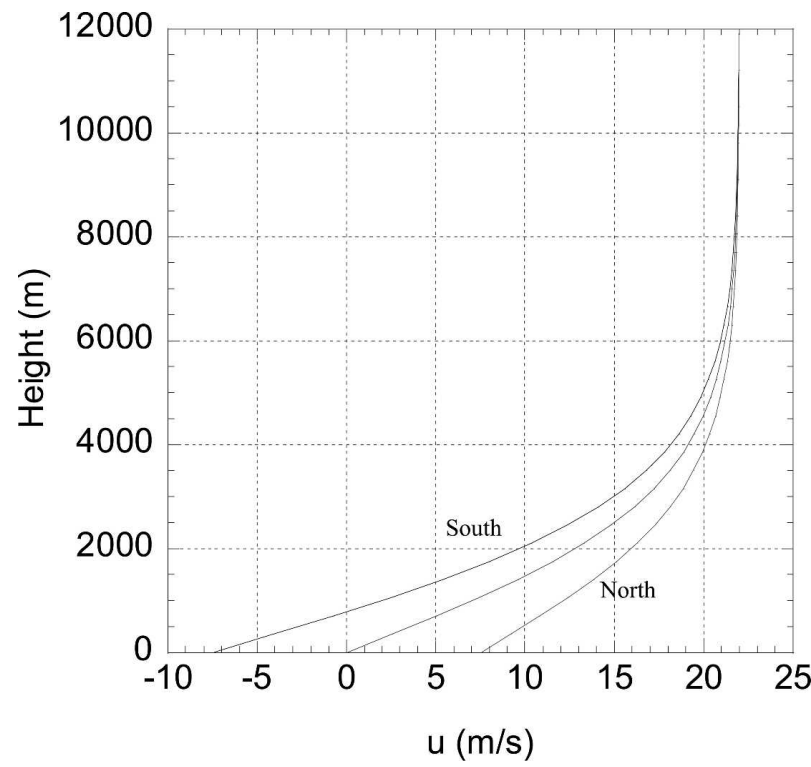

FIG. 8. Profile of east-west velocity component for inhomogeneous, unidirectional, moderate shear experiments. The middle line corresponds to the profile at the domain center, while the other two lines represent profiles at locations $75 \mathrm{~km}$ to the north and south of the domain center. 


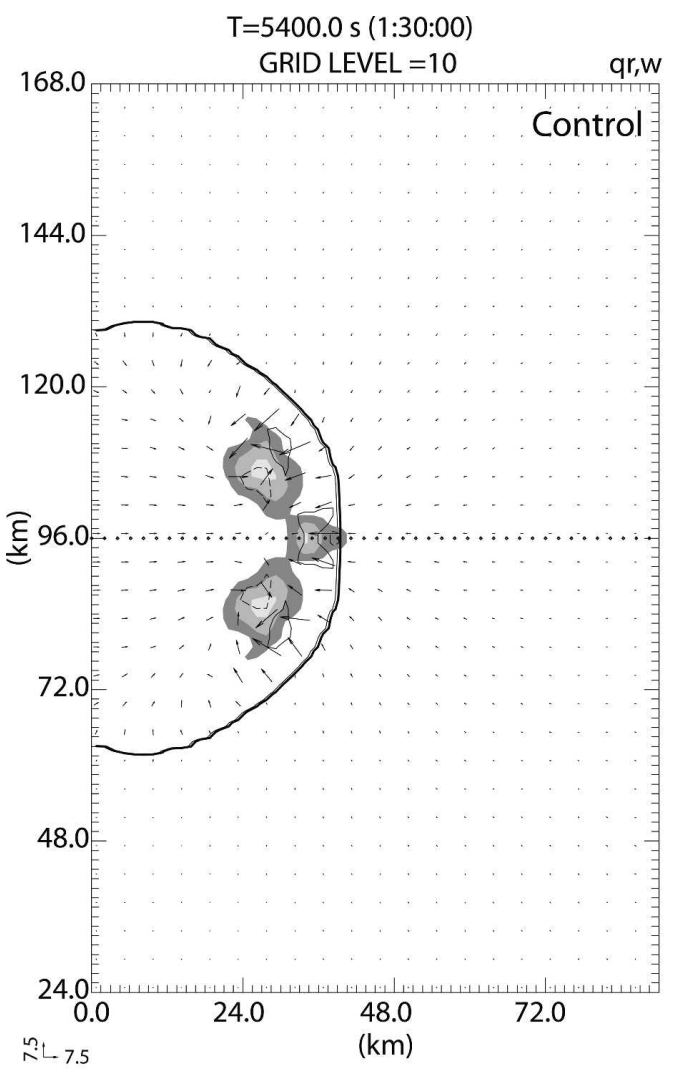

(a)

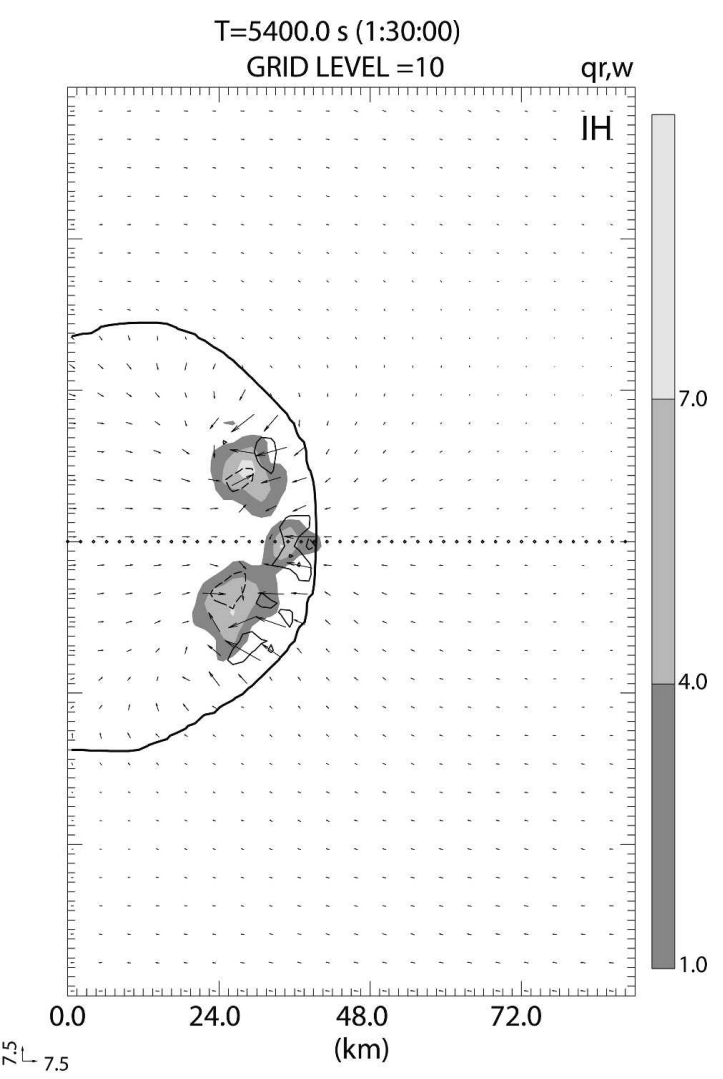

(b)

FIG. 9. Rainwater mixing ratio ( $\mathrm{g} \mathrm{kg}^{-1}$, shaded), vertical velocity $\left[5.0 \mathrm{~m} \mathrm{~s}^{-1}\right.$, thick contours, solid (dashed) for positive (negative) values, zero contour omitted] and storm-relative winds at $k=10(2.975 \mathrm{~km})$ for (a) the control run at $5400 \mathrm{~s}$ and (b) the inhomogeneous simulation at $5400 \mathrm{~s}$. Control simulation vertical shear corresponds to $U_{s}=22 \mathrm{~m} \mathrm{~s}^{-1}$ and the inhomogeneous simulation vertical shear is shown as in Fig. 8. The bold line indicates the surface gust front ( $-1 \mathrm{~K}$ perturbation potential temperature contour) and the dotted line indicates the symmetry line for the control simulation.

the velocity components; the other will then be determined by the base-state hodograph together with 13 . A viable environment for our purposes was determined by specifying

$$
V^{\prime}=-1.5 \times 10^{-4}\left[1-\tanh \left(z / z_{s}\right)\right]\left(x-x_{o}\right) \quad \mathrm{m} \mathrm{s}^{-1},
$$

along the line $\left[x-x_{o}=-\left(y-y_{o}\right)\right]$, yielding an environmental vertical vorticity profile given by

$$
\zeta(z)=-\frac{1.5 \times 10^{-4}\left[1-\tanh \left(z / z_{s}\right)\right]}{\sin ^{2} \beta(z)+\sin \beta(z) \cos \beta(z)} \mathrm{s}^{-1} .
$$

The solution specified in this manner will have a reasonable vertical profile (e.g., no spurious loops or jets with height) for $V$ across our domain. However, the profile can still be unreasonable for $U$ if $\cos \beta$ and $\sin \beta$ differ significantly. Thus, the base-state hodograph must have similar values for the two velocity compo- nents but must also have a significant change in wind direction with height in order to generate shear perturbations with a component along the mean wind. To satisfy goal 4 above, it also must have a sufficiently large mean wind. Very few wind profiles satisfy all of these constraints. The hodograph chosen above is thus a compromise in which the relatively small angle between shear variations and the mean wind is compensated by a large mean wind speed, reasonable hodograph variations (shown in section 6), and stability of the environment.

The direction of the base-state vertical shear is $45^{\circ}$ and $\beta(z)$, the orientation of the environmental streamlines in each level with respect to the $x$ axis, varies from $65.6^{\circ}$ at the surface to $51.6^{\circ}$ at $12 \mathrm{~km}$. The surface wind speed increases to the north-northwest across the domain. The horizontal gradient of wind speed diminishes and turns toward the northwest with height. Note that the gradient of vertical shear and the sign of the envi- 


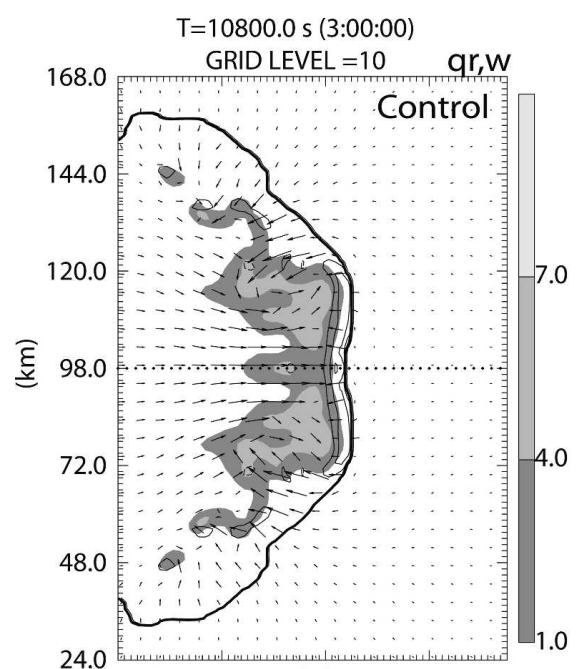

(a)

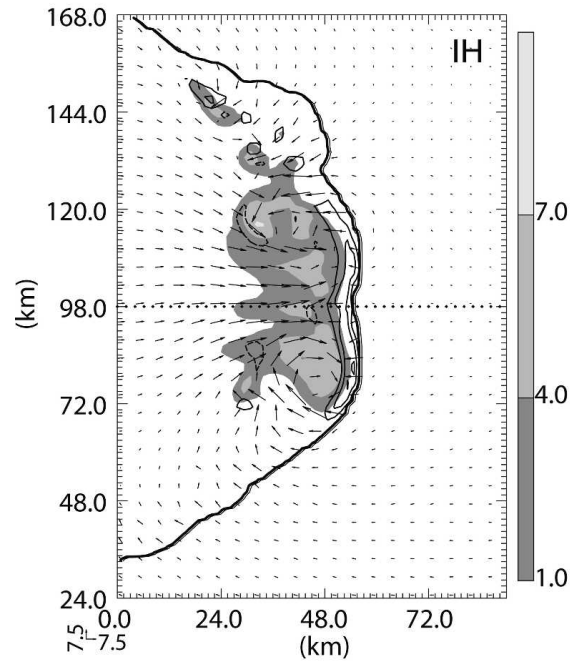

(c)

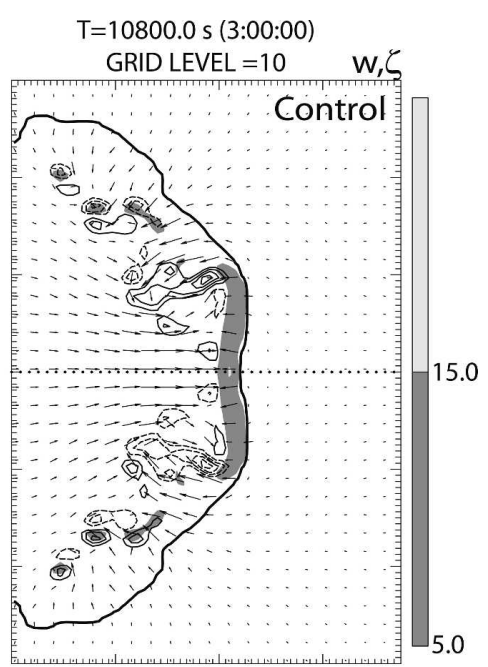

(b)

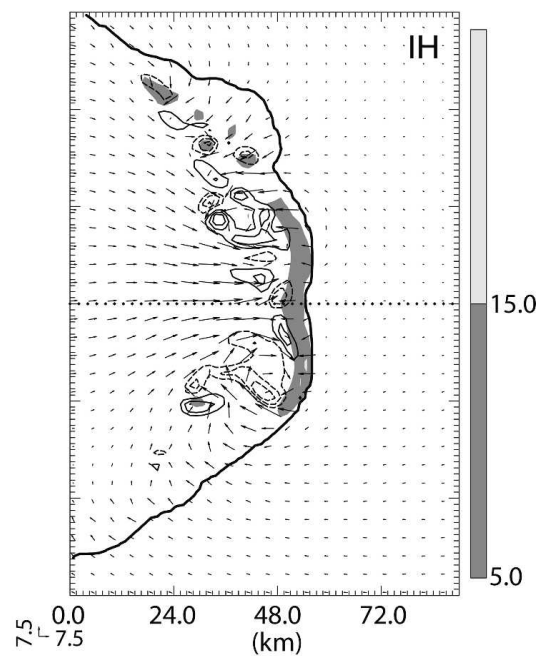

(d)

FIG. 10. Horizontal cross sections at $k=10(z=2.975 \mathrm{~km} \mathrm{AGL})$ depicting the rainwater mixing ratio, vertical velocity, storm-relative horizontal winds, and vertical vorticity at $3 \mathrm{~h}$ for (a), (b) the control simulation and (c), (d) the inhomogeneous simulation for the unidirectional, moderate shear case. In (a) and (c), the contours and shading are the same as in Fig. 9. For (b) and (d), dark shading represents the vertical velocities between 5 and $15 \mathrm{~m} \mathrm{~s}^{-1}$, light shading represents vertical velocities greater than $15 \mathrm{~m} \mathrm{~s}^{-1}$; vertical vorticity is contoured every $0.0025 \mathrm{~s}^{-1}$. The zero contour is omitted. The bold line indicates the surface gust front $(-1 \mathrm{~K}$ perturbation potential temperature contour) and the dotted line indicates the symmetry line for the control simulation.

ronmental vorticity cannot be varied independently. Thus, it is not possible, for example, to have the cyclonic member of a split pair move into a region of stronger vertical shear while residing in an environment characterized by positive environmental vorticity. We have chosen, admittedly arbitrarily, to characterize our environment with negative vertical vorticity in order to assess the response of the cyclonic member to increasing vertical shear over its lifetime. A similar response would be expected for the anticyclonic member if the environmental vorticity were positive instead.

This solution yields a nondivergent wind field. Although we recognize that convergence is present in most severe storm environments and may alter storm behavior significantly (e.g., Crook and Moncrieff 1988), we ignore such complicating factors here as they are not necessary to achieve our goal of understanding the influence of variable vertical shear on storm morphology. 


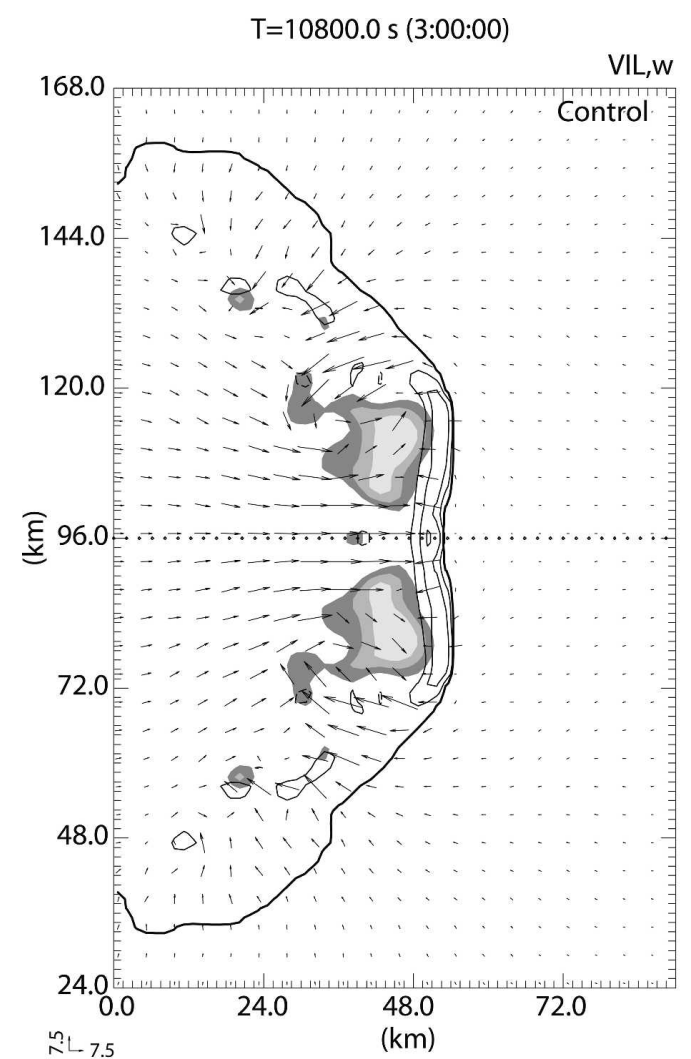

(a)

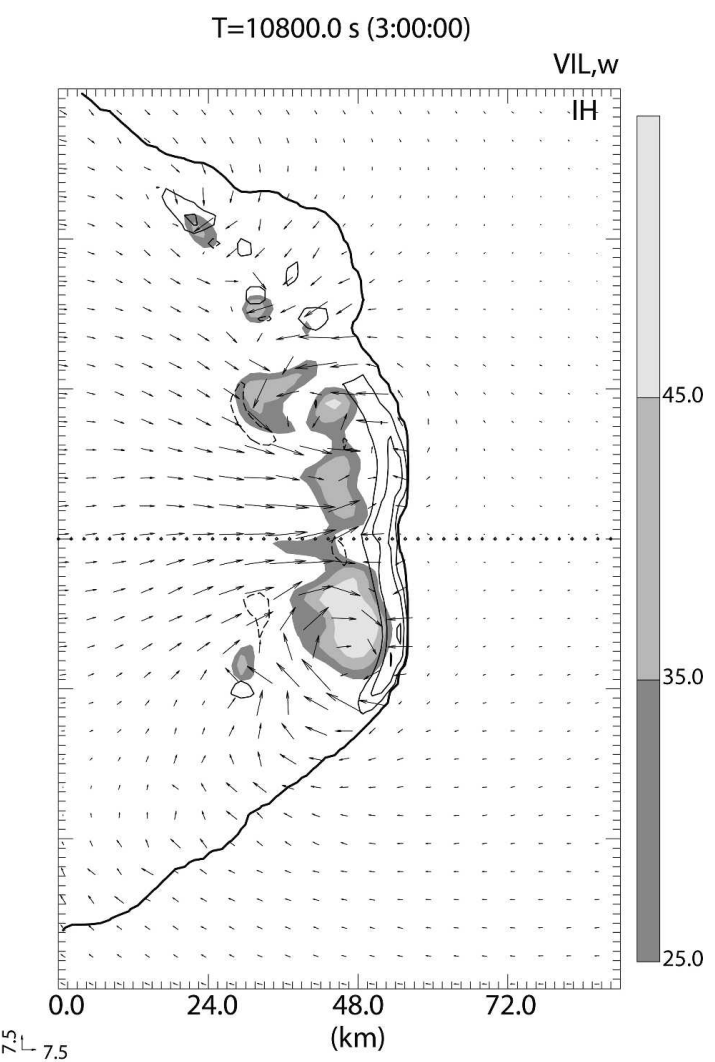

(b)

FIG. 11. Horizontal cross section of storm-relative horizontal winds and vertical velocity at $k=15(z=4.725$ $\mathrm{km}$ ), along with vertically integrated liquid water (VIL; $\mathrm{kg} \mathrm{m}^{-2}$, shaded) at $3 \mathrm{~h}$ for (a) the control simulation and (b) the inhomogeneous simulation with moderate, unidirectional vertical shear. The vertical velocity is contoured every $5 \mathrm{~m} \mathrm{~s}^{-1}$ [solid (dashed) for positive (negative) values, zero line omitted]. The bold line indicates the surface gust front $(-1 \mathrm{~K}$ perturbation potential temperature contour) and the dotted line indicates the symmetry line for the control simulation.

\section{Weak variable unidirectional vertical shear}

We first examine storm behavior in an environment where the base-state shear is weak (i.e., such that storm evolution is dominated by redevelopments along the outflow from the original storm). In this case, according to WK82, a homogeneous environment produces redevelopments downshear from the initial storm where the inflow and outflow winds most strongly oppose one another. With an inhomogeneous environment, the cold pool spreads into stronger shear on one side and weaker shear on the other. We seek to discover if this shear variability will enhance redevelopments on one of the flanks rather than in the downshear direction. The environmental winds for this case are given by

$$
\left(\begin{array}{l}
U \\
V
\end{array}\right)=\left[\begin{array}{c}
12 \tanh \left(z / z_{s}\right) \\
0
\end{array}\right]-\zeta\left[\left(y-y_{o}\right)\right]\left(\begin{array}{l}
1 \\
0
\end{array}\right)
$$

where $z_{s}$ is $3000 \mathrm{~m}$, and $\zeta$ is given by (15). The domain used is $90 \times 192 \times 20 \mathrm{~km}^{3}$, so $U$ varies from $2.4 \tanh \left(z / z_{s}\right) \mathrm{m} \mathrm{s}^{-1}$ to $21.6 \tanh \left(z / z_{s}\right) \mathrm{m} \mathrm{s}^{-1}$ from the northern boundary to the southern boundary, respectively (Fig. 3). (The multicell storm system actually occupies less than half the domain in the $y$ direction, so the variations in shear across it are much smaller than those implied for the entire domain.) The domain translation is toward the east at a constant value of $8 \mathrm{~m} \mathrm{~s}^{-1}$.

The shear variation prescribed by (20) is associated with small values of negative vertical vorticity in the environment. While we would prefer zero vertical vorticity, condition (13) cannot be met for a nontrivial wind profile without it. However, the general conclusions regarding redevelopments should not be significantly affected by the inclusion of environmental vorticity of this small magnitude.

Because the thermodynamic profiles in all simulations are horizontally homogeneous and the vertical wind 


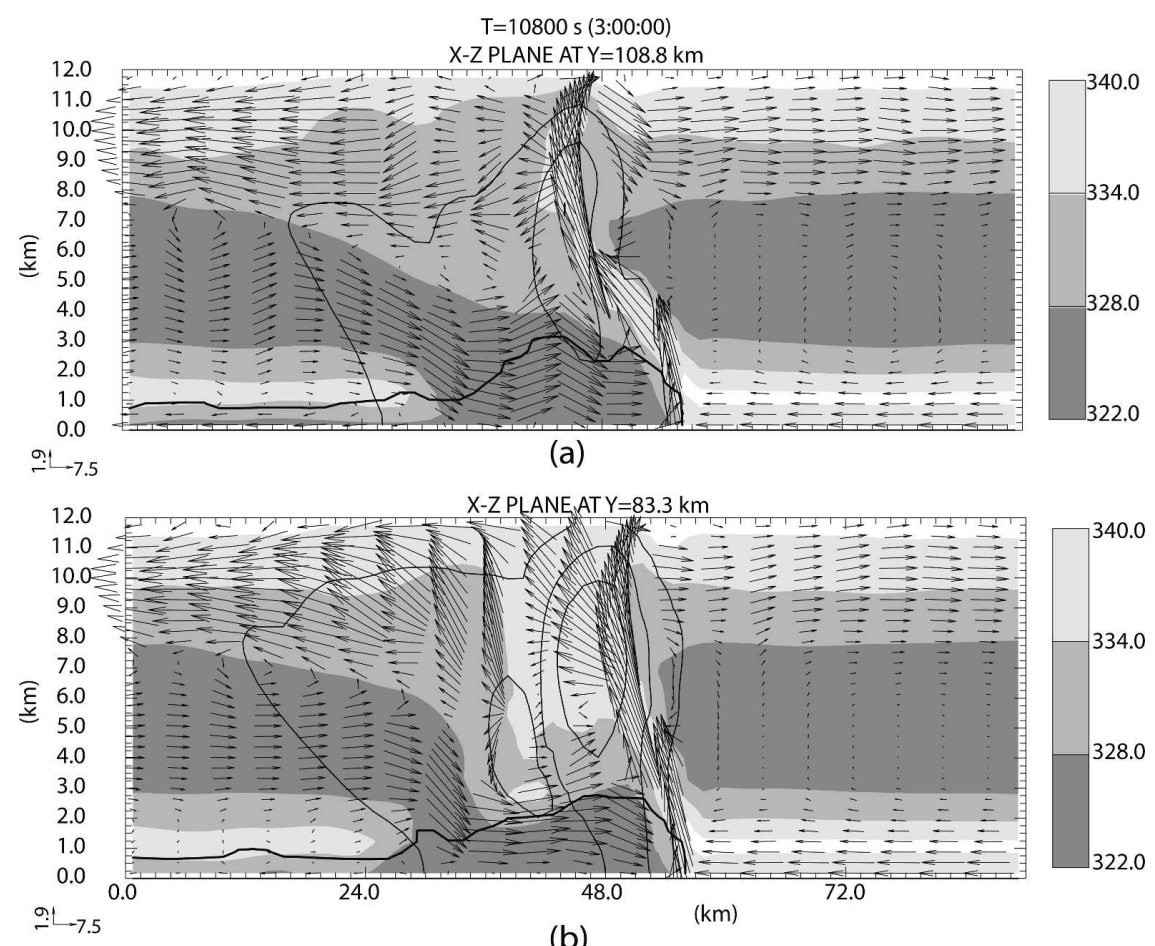

FIG. 12. Cross section of equivalent potential temperature (shaded), storm-relative winds, and rainwater at (a) $y=108.8 \mathrm{~km}$ and (b) $y=83.3 \mathrm{~km}$ at $10800 \mathrm{~s}$ for moderate $\left(U_{s}=22\right.$ $\mathrm{m} \mathrm{s}^{-1}$ ), unidirectional, inhomogeneous shear as in Fig. 8. The rainwater contours represent values of $0.5,4.0$, and $8.0 \mathrm{~g} \mathrm{~kg}^{-1}$. For the horizontal wind, a vector length of 3 tick marks is $15 \mathrm{~m} \mathrm{~s}^{-1}$. For the vertical wind, a vector length of 10 tick marks is $9.5 \mathrm{~m} \mathrm{~s}^{-1}$. The bold line indicates the $-1 \mathrm{~K}$ perturbation potential temperature contour near the surface.

shear is unidirectional, any significant north-south asymmetries that develop with respect to the original bubble latitude can be attributed to differences in the magnitude of the shear across the domain.

Figure 4 shows horizontal cross sections through the storm simulation at 4500 and $9000 \mathrm{~s}$. The resulting system remains quite symmetric for over an hour, with new cell development occurring in the downshear direction (toward the southeast). By $2 \mathrm{~h}$, however, the system has developed noticeable asymmetries, and at $2.5 \mathrm{~h}$ (Fig. 4b) more cells are present south of the original symmetry line than are present to the north. A corresponding enhancement of mass-weighted boundary layer $(0-2 \mathrm{~km})$ convergence is present along the southern flank of the gust front (Fig. 5b), where both the outflow winds and the vertical shear are greater and the cold pool is significantly stronger and slightly deeper (Fig. 6). This increased magnitude and depth of convergence aids the development of new cells on this flank, resulting in greater aerial coverage of rainwater. Interestingly, the strongest updraft at any particular time is not necessarily located south of the original symmetry line (Fig. 7) and cell lifetime is similar on both flanks. Thus, while cell development is enhanced by the stronger shear, updraft strength and longevity are not. The result suggests that, in this particular case, a multicell system may develop preferentially toward regions of higher shear while the strength and longevity of the individual updrafts remains fairly uniform across the system.

\section{Moderate variable unidirectional vertical shear}

We now examine storm evolution in an environment with stronger base-state vertical shear such that the environment at the center of the domain corresponds to the WK82 $U_{s}=22 \mathrm{~m} \mathrm{~s}^{-1}$ case and produces a split pair of storms as well as a secondary redevelopment along the symmetry axis in the downshear direction. This value of shear is purposely somewhat marginal for producing a splitting supercell storm so that, given the prescribed variations and the expected cell motions, the left-moving cell will encounter vertical shear values normally associated with multicells. Conversely, the right-moving cell will encounter vertical shear that is increasingly favorable to supercell development over its 


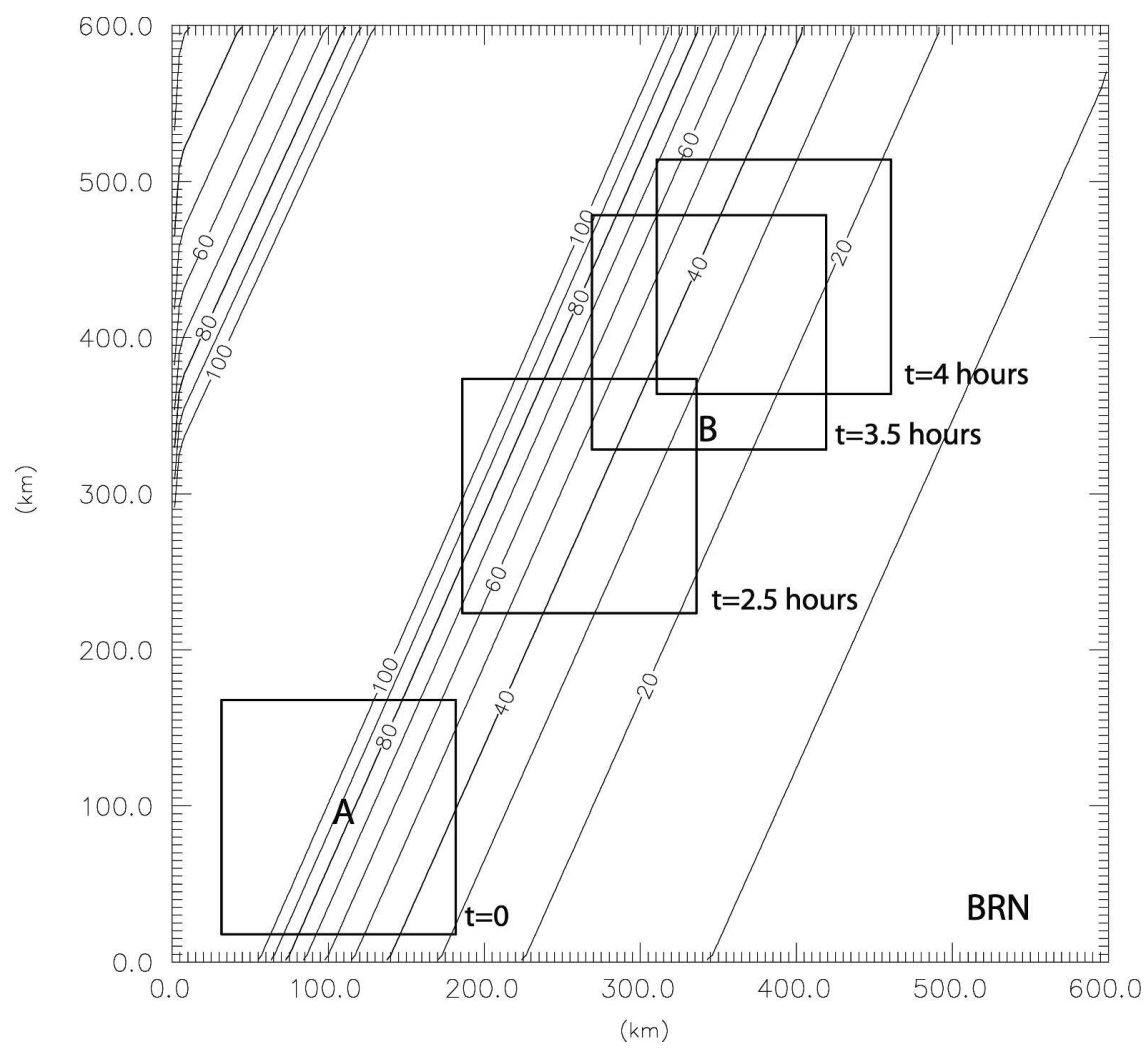

FIG. 13. Variation in the BRN (contoured every 10 between 0 and 100) for the theoretical environment in which shear varies along the mean wind. Actual computational domain locations within this environment at $0,2.5,3.5$, and $4 \mathrm{~h}$ are shown. Domain motions are constant between these times. Points A and B represent locations of the control run hodographs shown in Fig. 14.

lifetime. If the initial storm were started in a more strongly sheared environment, the variability in the environment (the magnitude of which is dictated by the need to keep vertical vorticity small) would not be great enough for the left-moving cell to reach conditions associated with multicells.

The environmental wind profile is given by

$$
\left(\begin{array}{l}
U \\
V
\end{array}\right)=\left[\begin{array}{c}
22 \tanh \left(z / z_{s}\right) \\
0
\end{array}\right]-\zeta\left[\left(y-y_{o}\right)\right]\left(\begin{array}{l}
1 \\
0
\end{array}\right)
$$

with $z_{s}=3000 \mathrm{~m}$ and $\zeta$ again described by (15). The magnitude of the environmental wind varies by 10 $\mathrm{m} \mathrm{s}^{-1}$ over $100 \mathrm{~km}$ at the ground and the horizontal variation falls asymptotically to zero aloft. This corresponds to an environmental vorticity value of $-\partial U / \partial y=$ $-10^{-4} \mathrm{~s}^{-1}$ at the ground. Although, again, we would prefer zero vertical vorticity in the environment, a nonzero value is unavoidable with the steady-state constraint. In the present configuration, the shear is strongest on the right side (with respect to the vertical shear vector), where we expect the cyclonic member of the original vortex couplet. If we observe a favoring of the right side, then, it is likely to be in spite of the anticyclonic environmental vorticity rather than because of it. The profile of $U$ at the domain center, as well as \pm 75 $\mathrm{km}$, is shown in Fig. 8. The domain translation is toward the east at a speed of $17 \mathrm{~m} \mathrm{~s}^{-1}$.

At $1.5 \mathrm{~h}$, the system remains fairly symmetric in lateral extent (Fig. 9), with the original split cells weakening somewhat while a new cell develops between them. Overall evolution at this time resembles that of the control run. By $3 \mathrm{~h}$ (Fig. 10), numerous cells have developed along northern portions of the gust front, where the shear is weaker but still sufficient for new cell development. The northernmost cells behave as typical multicells, while the linear structure closer to the symmetry line $(y=72-120 \mathrm{~km})$ consists of a steadier updraft and bookend vortices as described by Weisman (1993). The vorticity patterns near $z=3 \mathrm{~km}$ are somewhat similar for the two simulations, with both systems generating line-end vortices (Fig. 10) and having little correlation between vertical vorticity and vertical velocity. 


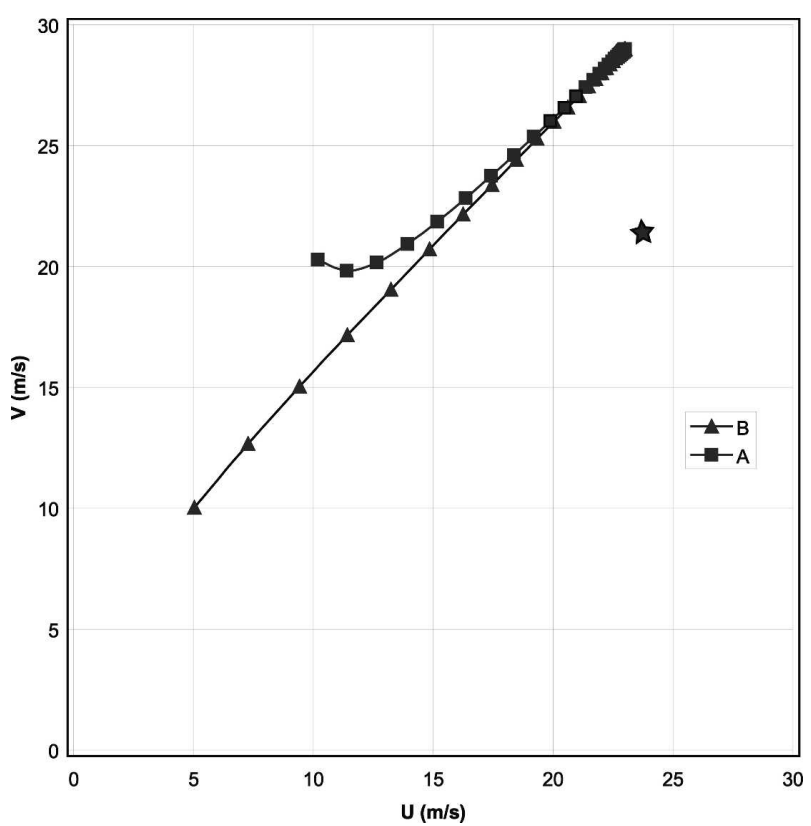

FIG. 14. Hodographs for domain locations shown in Fig. 13. Markers along lines indicate the individual model levels. The star indicates the motion of the strong right-moving cell between 2.5 and $3.5 \mathrm{~h}$ in the inhomogeneous simulation of section 6 .

Although the homogeneous and inhomogeneous simulations look somewhat similar at $3 \mathrm{~h}$ when only considering rainwater at one level, the differences become more evident when one considers vertically integrated values of rainwater (Fig. 11). In the inhomogeneous environment case, rain production is maximized in the southern half of the system where the shear magnitude is greater, the integrated boundary layer convergence is stronger, and the updraft is both larger and stronger. The principal cell south of the symmetry line is comparable to the cells in the homogeneous control run, but with no redevelopments to its south. North of the symmetry line, rain production is weaker compared to the control run, while the cold pool spreads farther from the original cells due to the additional weak cells to the north that are associated with a much weaker and shallower cold pool than in the central part of the system. In the inhomogeneous simulation, cold pool depth (as measured by the $-1 \mathrm{~K}$ perturbation potential temperature contour) is fairly symmetric about $y=96 \mathrm{~km}$ within $30 \mathrm{~km}$ north or south, but within this there is a larger area of negative potential temperature perturbations with magnitudes exceeding $8 \mathrm{~K}$ near the surface to the south. The updraft $12.8 \mathrm{~km}$ north of the domain center is tilted over the gust front compared to its more erect counterpart the same distance to the south (Fig. 12), and it has a much smaller region of large equivalent potential temperature aloft.
Thus, in this case of stronger environmental shear, the effect of shear variation is to favor new cell development on the weaker shear flank while increasing the organization of cells on the stronger shear flank, leading to increased rain production and a steadier, stronger updraft on the latter. The pattern of cells predicted here is not uncommon in observed storm systems, with one cell of greatest strength on the end of a line of weaker cells. Inhomogeneous vertical shear may be one mechanism for generating this pattern.

\section{Variable vertical shear along the mean wind}

The previous shear configurations are limited in that the shear can vary only along the direction perpendicular to the wind. This prevents the study of an entire system moving from weaker into stronger shear. To overcome this limitation, we now configure the environment such that the shear changes along the mean wind, and we examine a multicell storm system that encounters increasing shear over its lifetime. The environmental wind and vertical vorticity profiles used are given by (16)-(19).

This produces a change in BRN shown in Fig. 13. This figure also shows the horizontal extent of the computational domain $\left(150 \times 150 \mathrm{~km}^{2}\right)$ and its position within this larger environment over the 4-h integration. Hodographs valid at two locations in the environment are shown in Fig. 14. The domain translation $\left(C_{x}, C_{y}\right)$ is $(17,23) \mathrm{m} \mathrm{s}^{-1}$ from 0 to $2.5 \mathrm{~h},(23,29) \mathrm{m} \mathrm{s}^{-1}$ from 2.5 to $3.5 \mathrm{~h}$, and $(23,19) \mathrm{m} \mathrm{s}^{-1}$ from 3.5 to $4 \mathrm{~h}$. To simplify the interpretation, an average value of $(22.5,26.5) \mathrm{m} \mathrm{s}^{-1}$ is subtracted to produce winds in the figures that are essentially storm relative.

To aid our interpretation of the change in storm behavior due to the prescribed change in environmental shear, we first perform a homogeneous simulation using the shear profile valid at the storm initiation location (see profile A in Figs. 13-14). The thermodynamic profile and the domain motion are identical to those in the inhomogeneous case. In the control simulation, the initial updraft splits (Figs. 15a,b), with slight favoring of the left-moving cell as expected given the slight counterclockwise curvature in the hodograph (Rotunno and Klemp 1982). At $1.5 \mathrm{~h}$, the original updrafts still exist and remain correlated with weak vertical vorticity (Figs. 16a, b). New cells are beginning to form and become more evident at $2 \mathrm{~h}$ (Figs. 17a,b). By $2.5 \mathrm{~h}$, the system has become multicellular (Figs. 18a,b), and this general behavior continues in a classic pattern for the duration of the simulation (as shown in Figs. 19a,b21a,b).

We compare this experiment with another homogeneous simulation using a sounding corresponding to the 

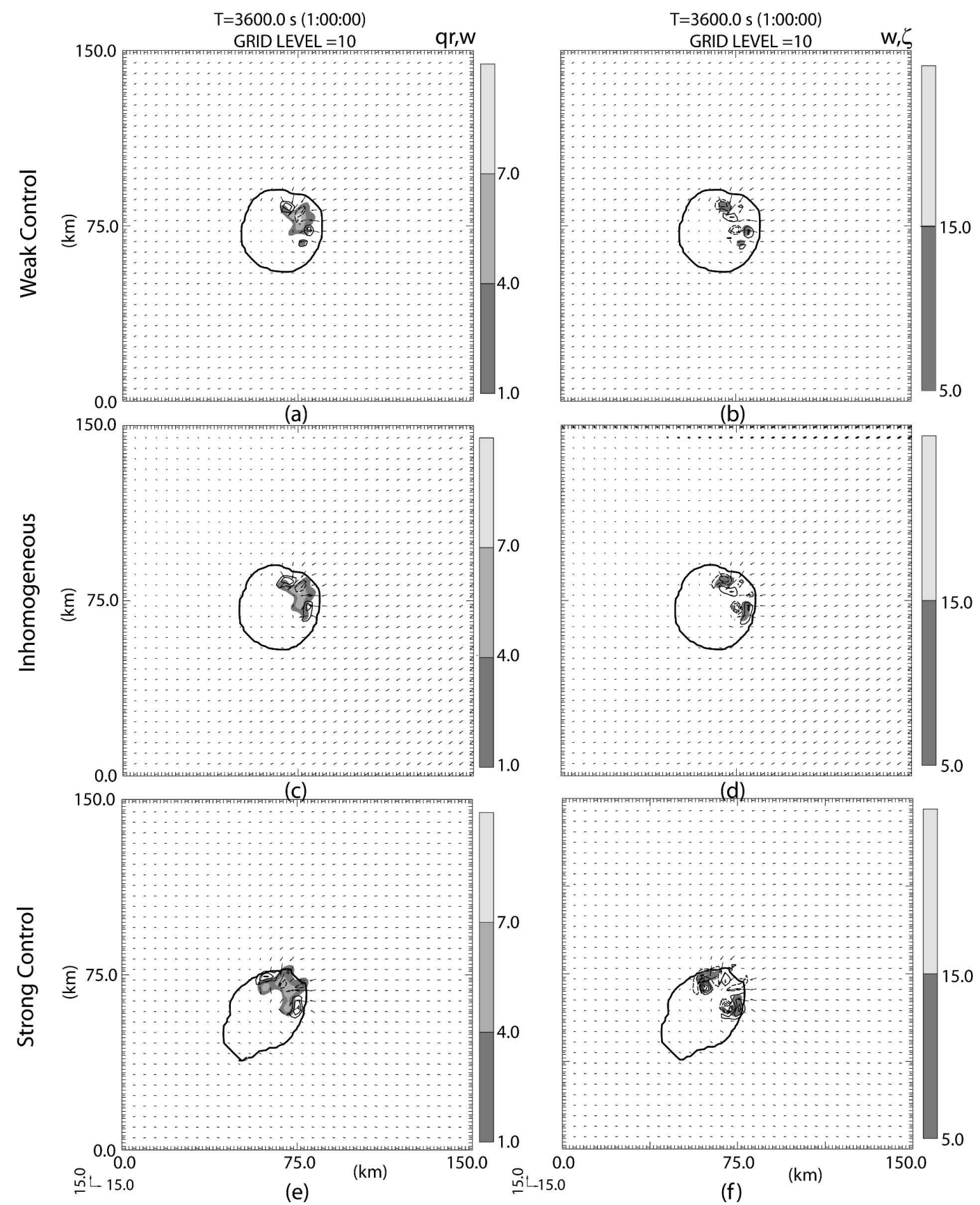

FIG. 15. Horizontal cross sections at $1 \mathrm{~h}$ at grid level $10(z=2.975 \mathrm{~km})$ for (a), (b) control run using profile A in Fig. 14; (c), (d) the inhomogeneous simulation using domain shown in Fig. 13; and (e), (f) the control run using profile B in Fig. 14. Plots are the same as in Fig. 10.

3-h position of right-flank cells in the inhomogeneous domain (see profile B in Figs. 13-14). The domain motion for this control run is $(17,23)$ from 0 to $3 \mathrm{~h}$ and $(23$, 19) from 3 to $4 \mathrm{~h}$ [an average value of $(21.5,24.5)$ is subtracted in the figures]. Storm behavior for this wind profile is quite different from the weaker shear control run noted above, producing more traditional splitting supercells during the first 2 h (Figs. 15e,f; Figs. 16e,f; Figs. 17e,f). As the cold pool continues to strengthen, the split cells become elongated along the gust front. The original right-moving cell develops strong bookend vortices by $2.5 \mathrm{~h}$ (Fig. 18f), and by $3 \mathrm{~h}$, both of the original updrafts retain some correlation with vertical vorticity, though the bookend vortices continue to be 

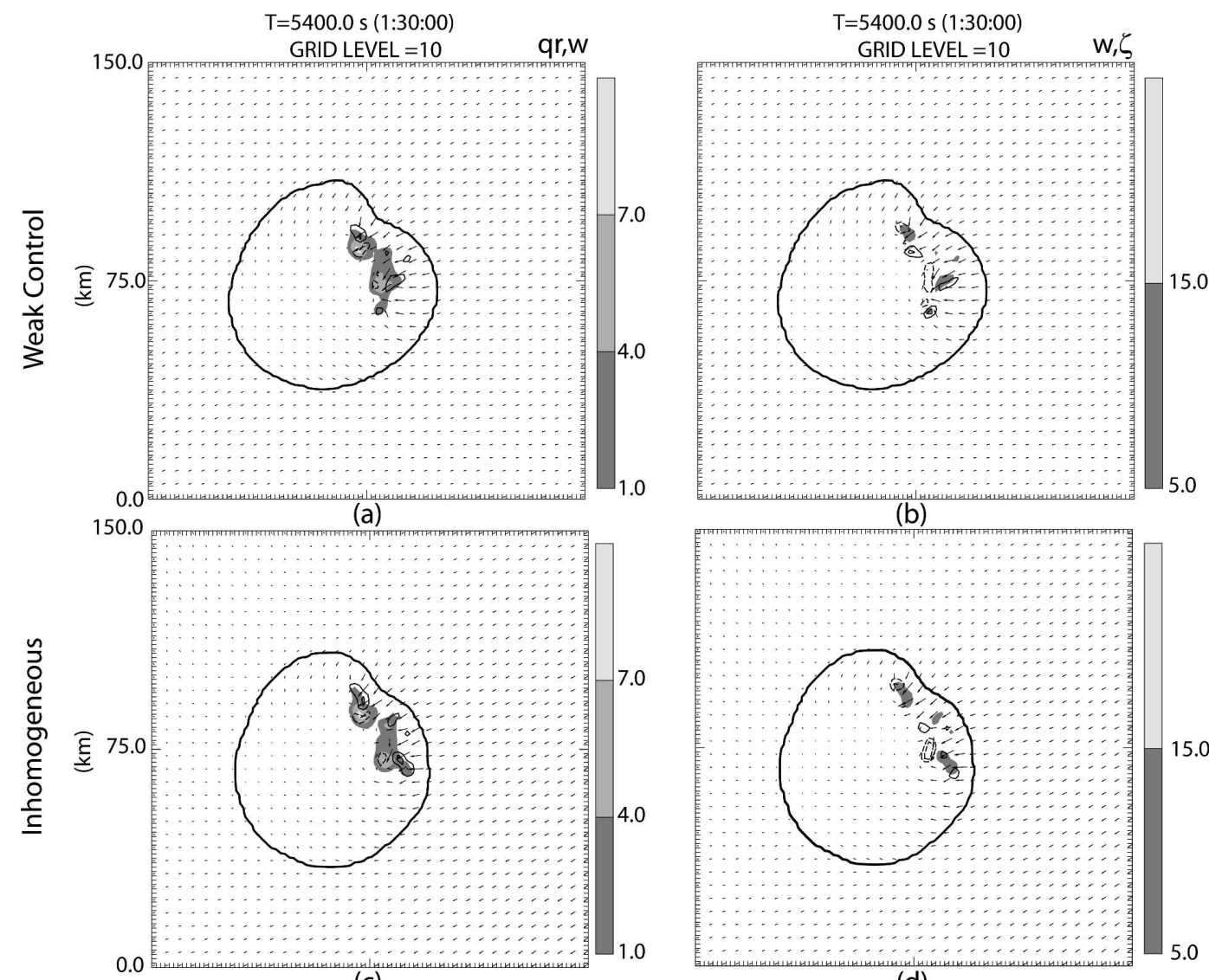

(b)
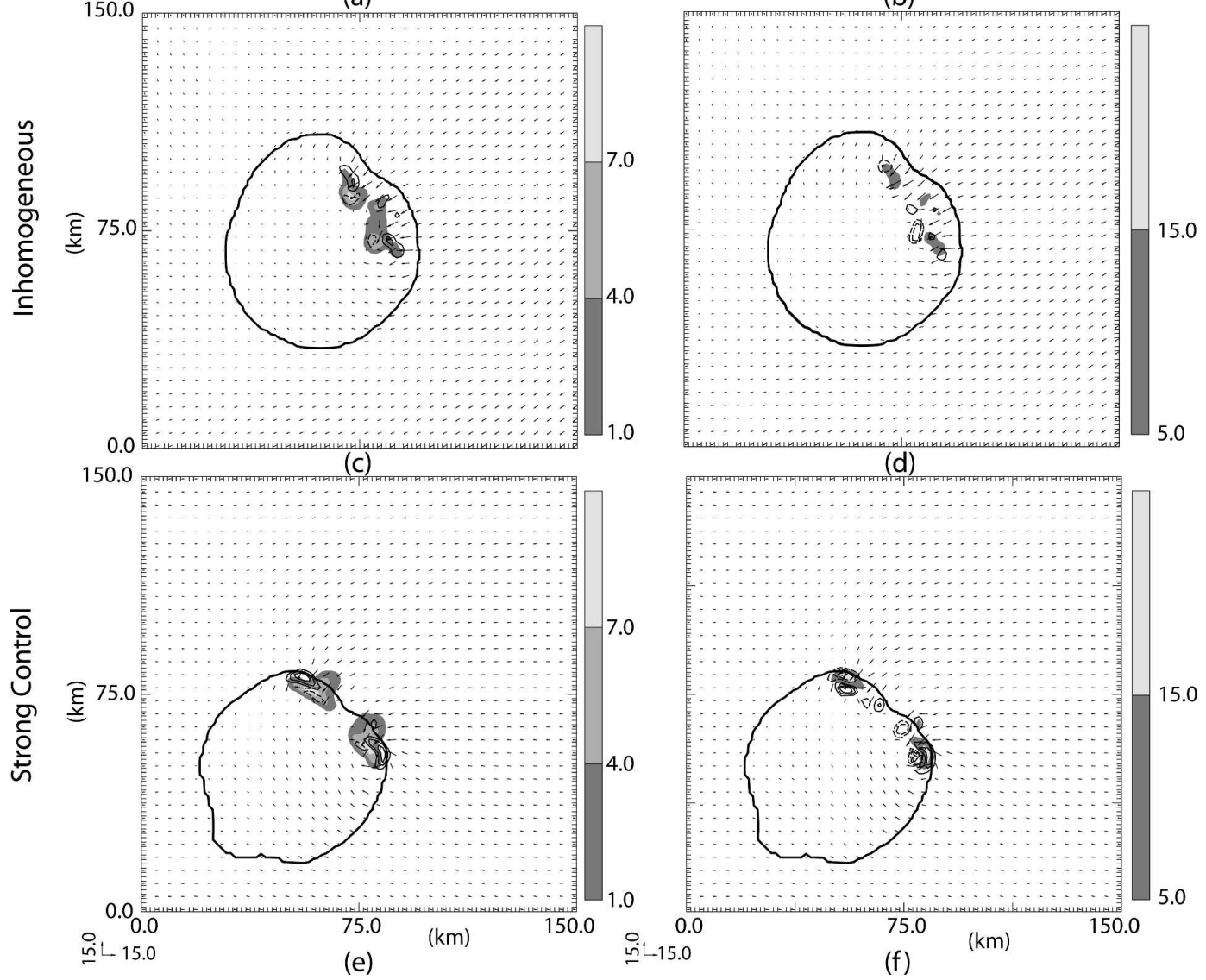

(d)

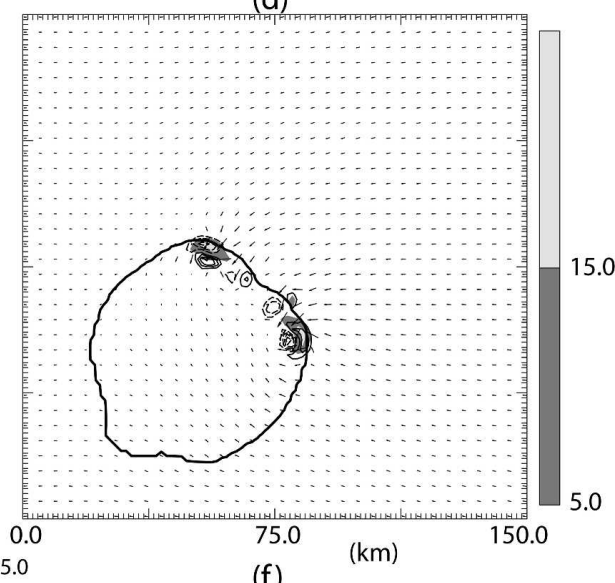

FIG. 16. Same as in Fig. 15, but at $1.5 \mathrm{~h}$.

the dominant features (Fig. 19f). At $4 \mathrm{~h}$, both of the original split cells have the appearance of bow echoes with elongated, fairly steady, bowed updrafts, bookend vortices, and significant rear inflow (Figs. 21e,f). The storms in this simulation show a greater degree of steadiness and longevity than those in the weak shear control run. The compelling issue is whether a storm initiated in the original weak shear environment, then moving into the strong shear environment, will also be- come organized in such a manner, or if it will continue to exhibit multicellular structure.

The storm initiated in the inhomogeneous environment behaves very similar to the weak shear control run for the first $2 \mathrm{~h}$ (Figs. 15c,d; Figs. 16c,d; Figs. 17c,d), with the original updraft splitting into two updrafts that gradually are overtaken by the gust front. The cell on the strong shear flank is closer to the gust front and has increased rainwater $\left(q_{r}>7 \mathrm{~g} \mathrm{~kg}^{-1}\right)$ at $3 \mathrm{~km}$ than cells 

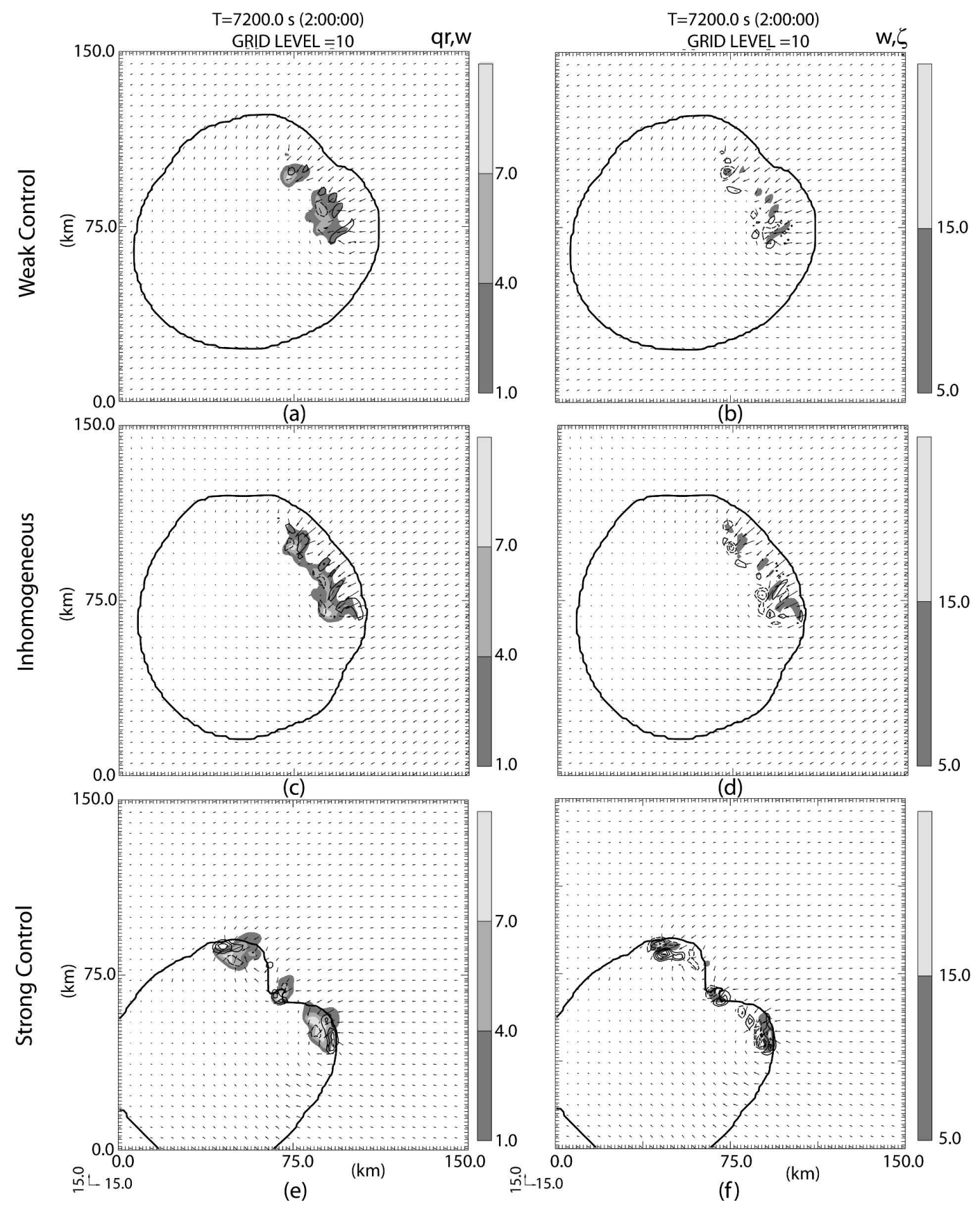

FIG. 17. Same as in Fig. 15, but at $2 \mathrm{~h}$.

similarly located in the weak shear control run, but is weaker and less correlated with vertical vorticity than cells in the strong shear control run (Figs. 17c,d).

As the system continues to move into stronger shear, its structure diverges more and more from that of the weak shear control run. Although both the weak shear control run and the inhomogeneous run produce a line of cells at $2.5 \mathrm{~h}$, the cells are significantly stronger in the inhomogeneous case, with the cell near $y=75 \mathrm{~km}$ more closely resembling cells in the strong shear control run (Fig. 18). Storm structure at this time resembles that of the idealized simulation with a straight hodograph and a shear variation across the storm (section 5), with a similar organizing influence on the strong shear flank. In this case, the increased shear allows the original right-moving cell to maintain its position along the gust 

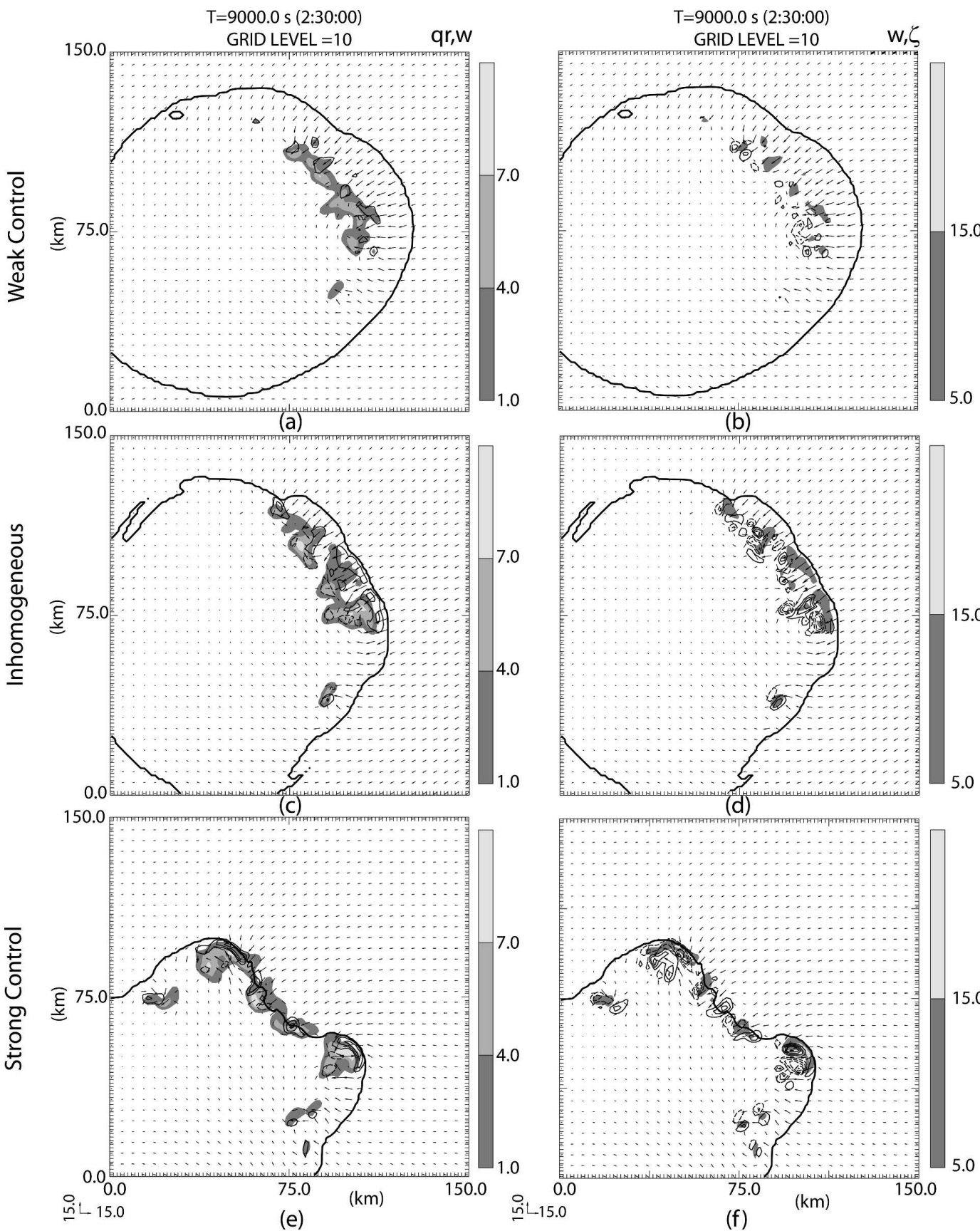

(b)

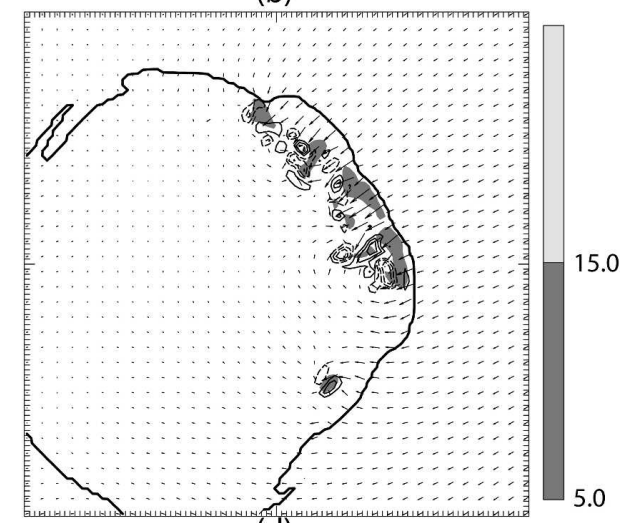

(d)

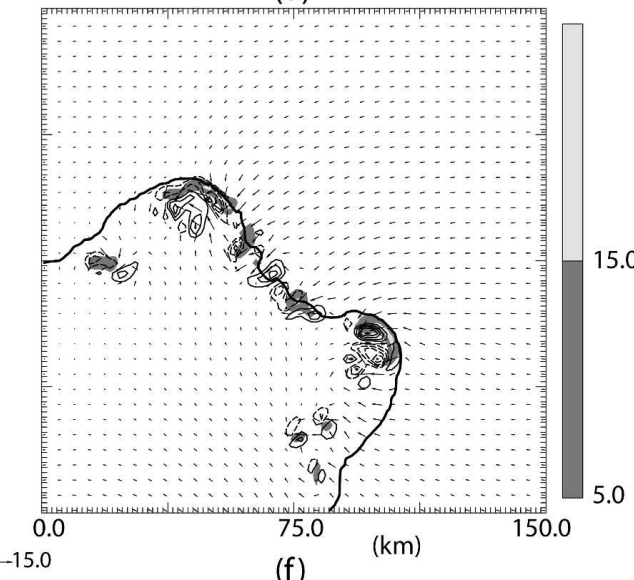

FIG. 18. Same as in Fig. 15, but at $2.5 \mathrm{~h}$.

front much longer than in the weak shear control run, and with a larger, stronger updraft that produces more rain.

As the storm system continues to move into stronger vertical shear at $3 \mathrm{~h}$, the updraft structure changes from one of cellular convection to one of linear slab convection with local maxima along, and rear inflow developing behind, the nose of the gust front. Vertical vorticity at $3 \mathrm{~h}$ (Fig. 19d) is quite complex at $z=3 \mathrm{~km}$, with both systemwide and local bookend vortices associated with downdrafts. These features are in stark contrast to those in the weak shear control run (Fig. 19b), which remains dominated by small updrafts associated mainly with vortex couplets. They also differ from the strong shear control run (Fig. 19f), which shows the original split pair evolving into two bow echoes, each associated with a pair of bookend vortices.

The inhomogeneous simulation shows continued 

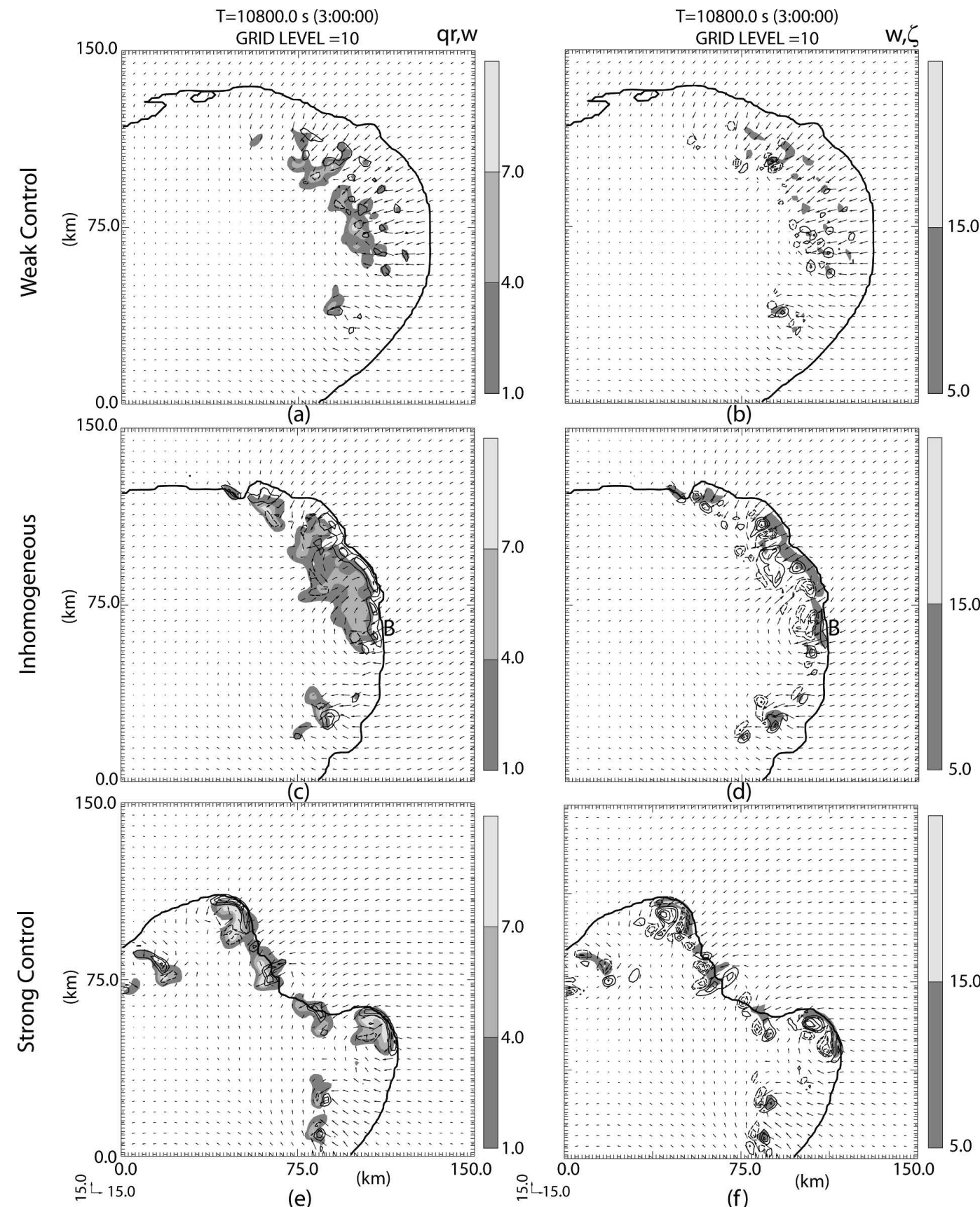

(b)

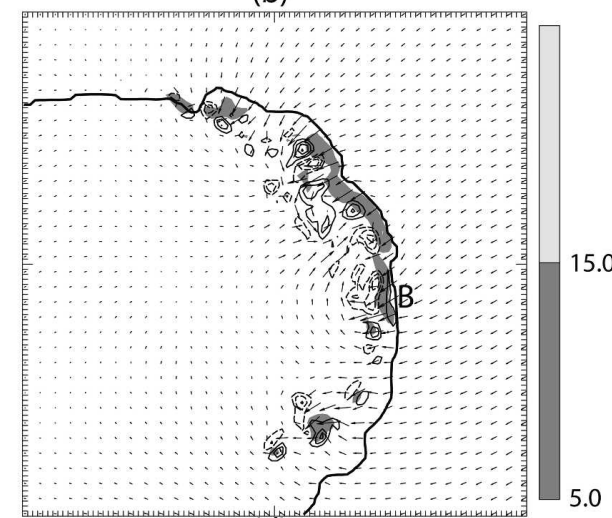

(d)

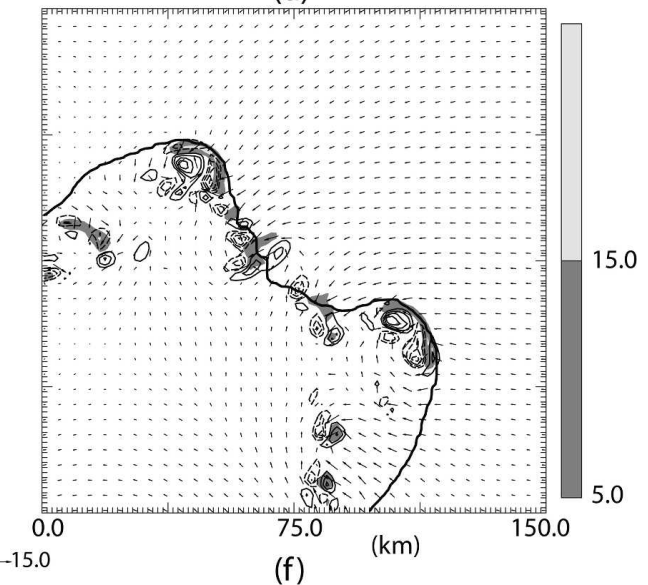

FIG. 19. Same as in Fig. 15, but at 3 h. (c), (d) The "B" indicates the location at which the initial wind profile is given by hodograph B in Fig. 14.

change in structure as the system progresses into stronger shear. By 3.5 h (Fig. 20), the linear convection area now dominates along the gust front, with a maximum at the midpoint of the region and greater overall intensity ( $w>15 \mathrm{~m} \mathrm{~s}^{-1}$ at $3 \mathrm{~km}$ over a larger area) than before. The rear inflow also has strengthened and extends farther behind the system, while vertical vorticity has evolved into a coherent pair of bookend vortices. The rainwater at $z=3 \mathrm{~km}$ shows some increase as well and also has taken on a bowed shape.

At $3.5 \mathrm{~h}$, the strong cell near the southern edge of the inhomogeneous domain is fairly isolated from the bow echo system and appears very similar to the rightmoving cell at $1.5 \mathrm{~h}$ in the strong shear control run (cf. Figs. 16e,f). The former is first evident around $2.5 \mathrm{~h}$ and continues to develop with significant rainfall $\left(q_{r}>\right.$ 

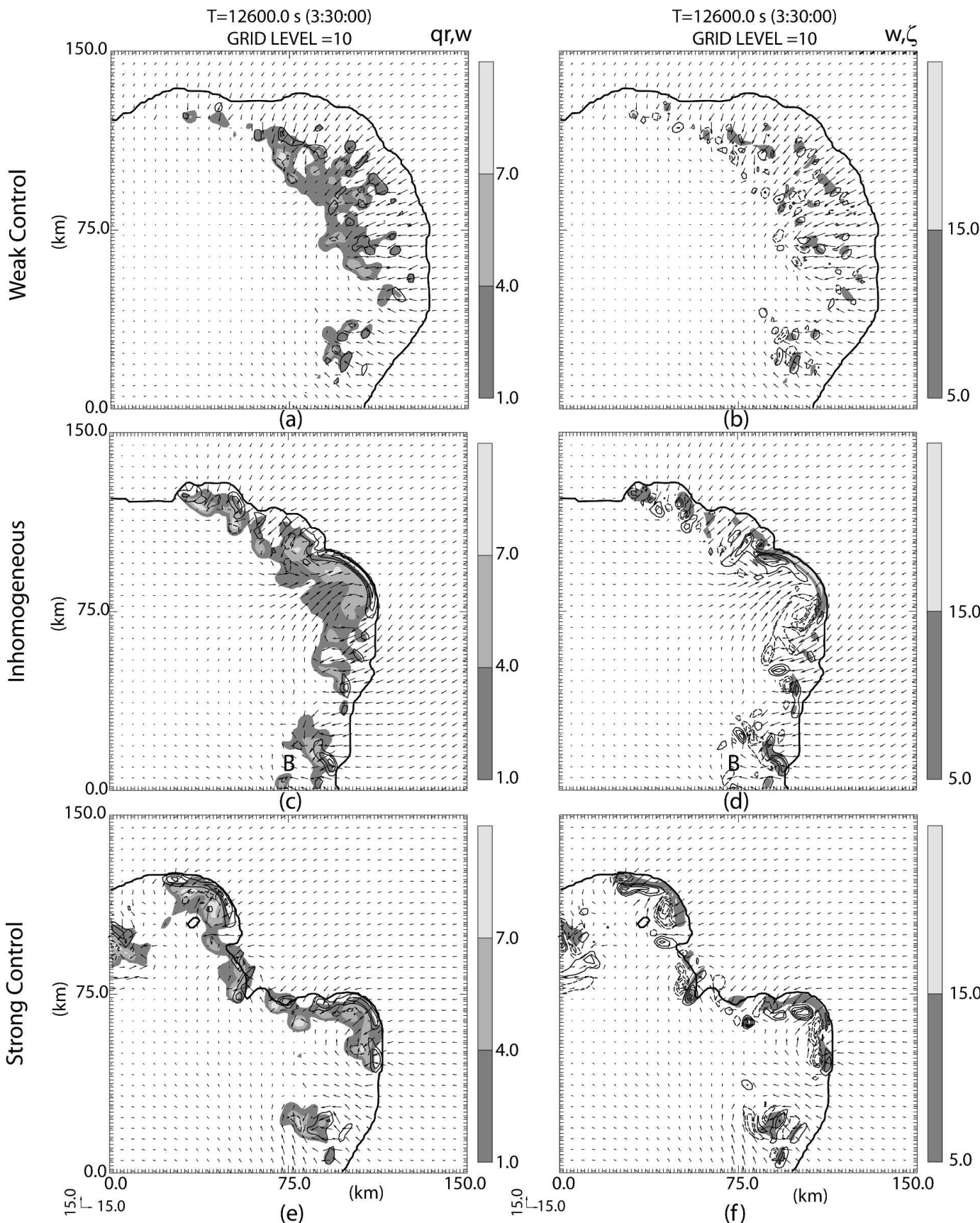

(b)

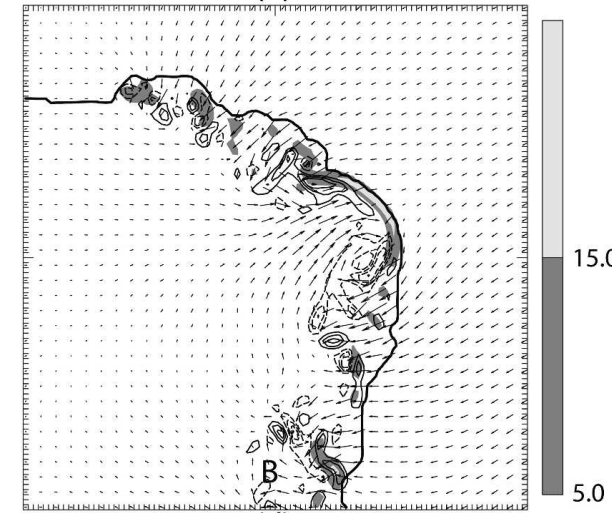

(d)

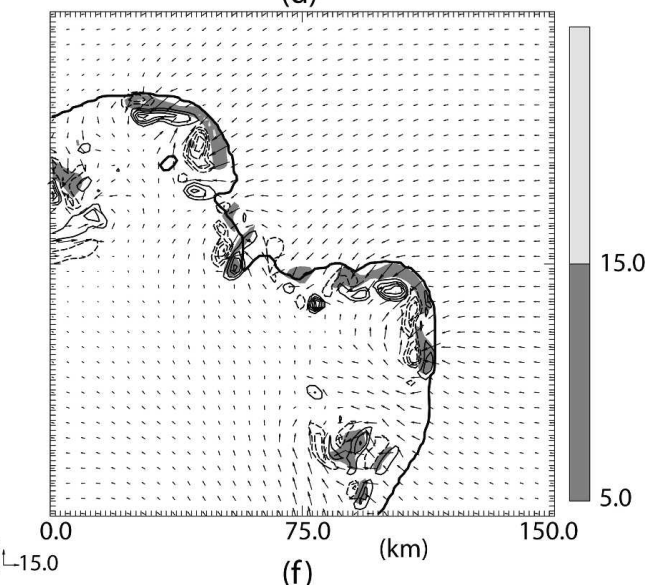

FIG. 20. Same as in Fig. 15, but at 3.5 h. (c), (d) The "B" indicates the location at which the initial wind profile is given by hodograph B in Fig. 14.

$7 \mathrm{~g} \mathrm{~kg}^{-1}$ at $3 \mathrm{~km}$ ) and substantial vertical vorticity ( $\zeta>$ $7.5 \times 10^{-3} \mathrm{~s}^{-1}$ at $3 \mathrm{~km}$ ) until the end of the simulation. It is possible that the proximity of this cell to the domain lateral boundary had some influence on its evolution. To eliminate this possibility, the inhomogeneous simulation was repeated in a larger domain. At $4 \mathrm{~h}$, the bow echo structure is virtually unchanged and is not shown. Instead, we focus on the southern cell (Fig. 22), which is also very similar to its counterpart in the original small domain simulation. This cell continues to maintain its position near the gust front, and its midlevel correlation between vertical velocity and vertical vorticity remains high. However, the development of cyclonic low-level rotation is complicated by the en- 

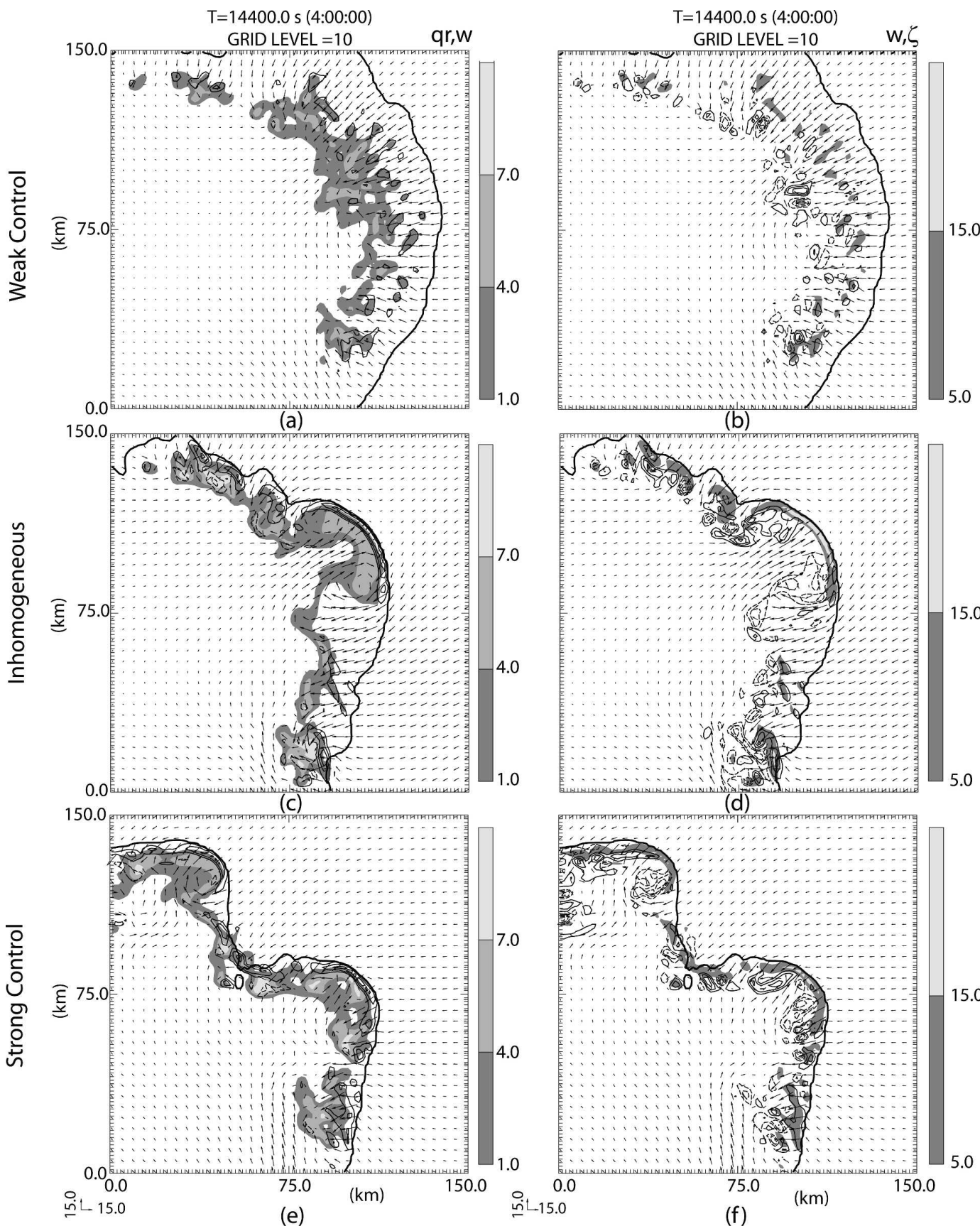

(b)

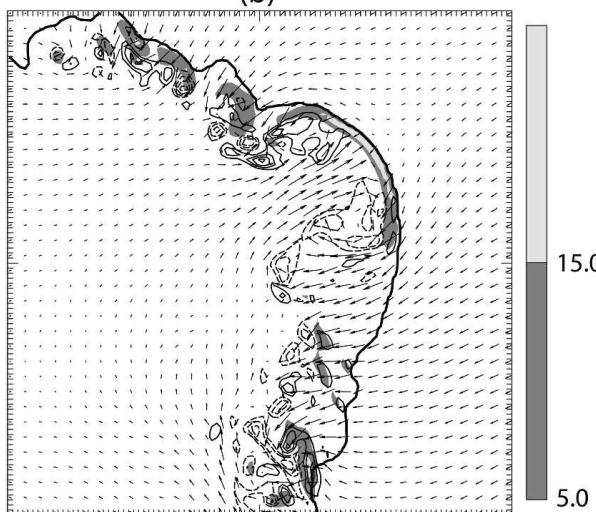

(d)

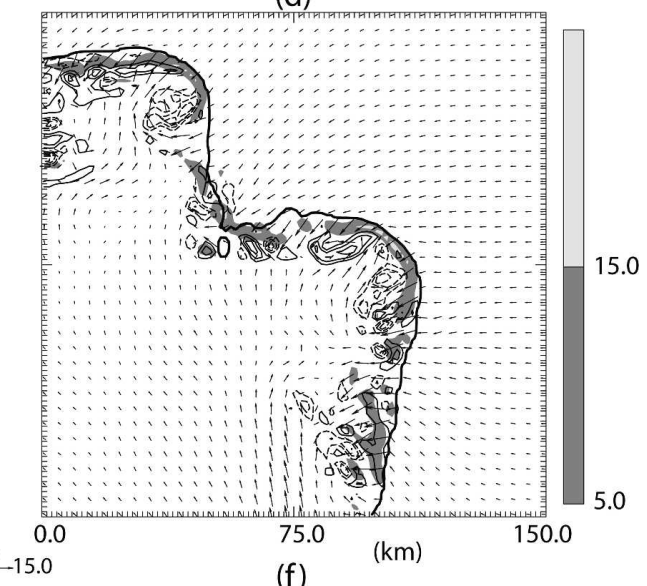

FIg. 21. Same as in Fig. 15, but at $4 \mathrm{~h}$.

vironmental negative vorticity that is contracted due to convergence along the gust front. Therefore, no conclusions regarding low-level rotation can be made.

Comparing the inhomogeneous simulation to the control run corresponding to the original bubble location, we conclude that the change in shear over the lifetime of the storm system has had a profound impact on the storm structure, changing it from one dominated by ordinary cellular convection to one dominated by quasi- linear convection associated with a bow echo. Only an isolated cell sufficiently removed from the bow in a region of strong shear takes on supercellular characteristics (e.g., net midlevel updraft rotation).

One may question whether the change in storm structure can be attributed predominantly to the change in vertical shear experienced by the storm system over time or whether there is an additional significant influence from the prescribed environmental vorticity. To 

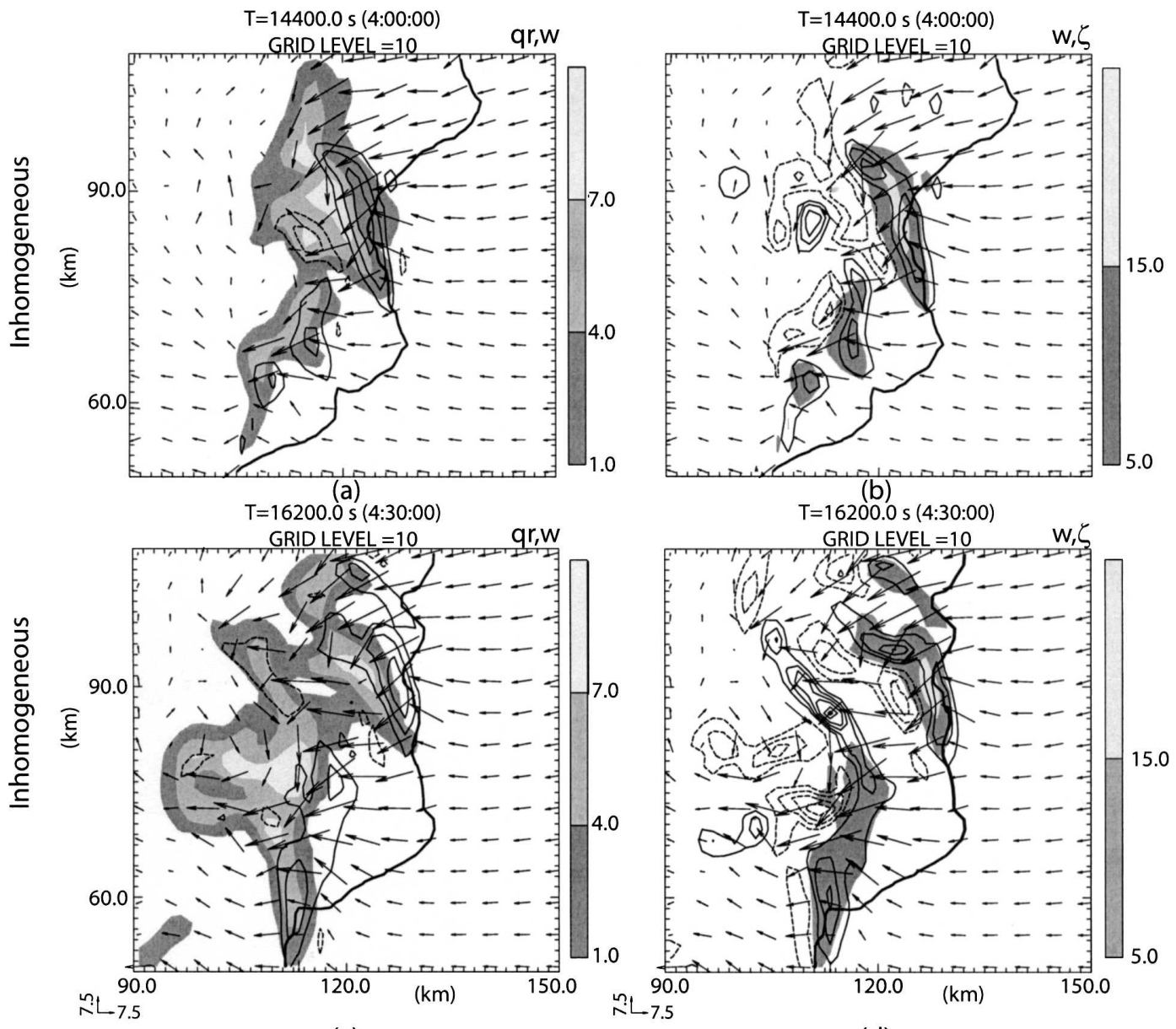

(b) $T=16200.0 \mathrm{~s}(4: 30: 00)$

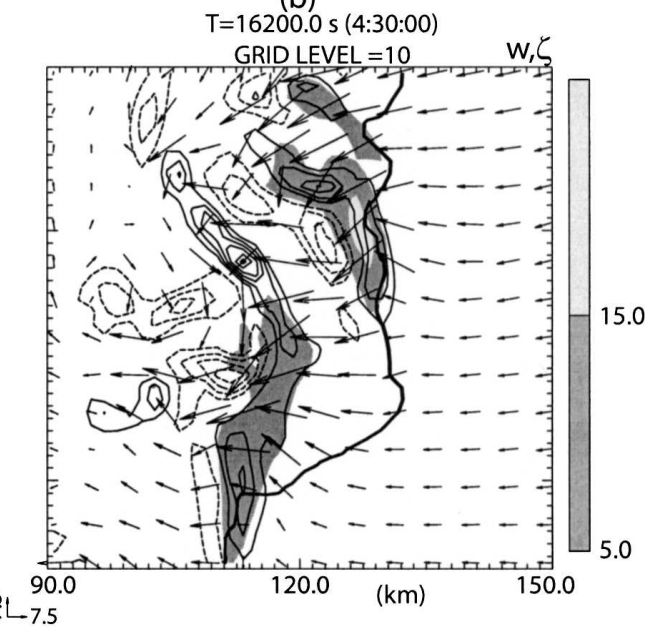

(c)

(d)

FIG. 22. The inhomogeneous simulation of section 6 in large domain at (a) 4 and (b) $4.5 \mathrm{~h}$. Plots are the same as in Fig. 10. Only a portion of the domain is shown.

separate the two influences, we performed a horizontally homogeneous simulation in which the vertical shear is forced to change in time over the entire domain at the same rate as experienced at the nose of the gust front in the inhomogeneous simulation. This is accomplished by adding a time-tendency term to the $u$ and $v$ momentum equations. In this case, the storm system is again found to evolve from a multicell system to a bow echo in a manner nearly identical to that of the inhomogeneous simulation. Thus, we are confident it is the change in vertical shear experienced over the lifetime of the storm, rather than an influence of the environmental vorticity, that results in the observed storm system evolution.

\section{Conclusions}

In this study, we bridge the gap between horizontally homogeneous simulations and those using environments constructed from numerous types of observa- tions by specifying horizontal variations in environmental vertical shear in an idealized, controlled manner so that their influence on storm morphology can be readily diagnosed. Simulations are made in weak unidirectional shear, moderately strong unidirectional shear, and shear chosen such that variations in shear along the mean wind are possible. Modifications to the numerical model are accomplished to accommodate these variations.

Variations in environmental vertical wind shear are found to profoundly influence the morphology of deep convective storms. When convection is initiated in weak shear, with shear varying across the resulting storm system, the development of new cells tends to be favored on the higher shear flank of the gust front where convergence is enhanced. The midlevel updraft strength, however, is not necessarily larger on this flank. Thus, we might expect a storm system to appear to expand toward the greater shear flank. 
When a storm is initiated within the same shear configuration but with larger values of shear, new cell growth is preferred on the weaker shear side, but storms on the strong shear side show greater organization and longevity. New cell development is prevented wherever the shear exceeds a threshold value on one side of the storm, in agreement with WK82, but continues on the other side. Thus, we might expect a storm system to appear to expand toward weaker shear, where redevelopment cells are likely, while it maintains the most organized cells on the greater shear side.

When an entire storm system moves into increasing shear over its lifetime, the overall system structure is affected as disorganized multicells form coherent structures of greater vorticity and intensity. This represents a new way to develop a feature such as a bow echo from existing cells that were not originally supercells as opposed to those formed in Weisman (1993), in which "cases that eventually evolve into bow echoes all originate with splitting cells earlier in the lifetime of the system." While the system in our simulation did begin with weakly splitting cells, the bow echo did not evolve from one of the members of the split pair, but rather from disorganized cells from the subsequent multicell system. Only a relatively isolated cell forming away from the main bow echo in strong shear develops supercellular characteristics.

This study represents only the first step toward understanding the response of storms to inhomogeneous environments. A comparison of these results with those based on horizontally homogeneous but temporally varying environmental vertical shear might provide the best method of analysis, since such a methodology allows greater flexibility in hodograph choice (e.g., allowing for changes in hodograph curvature) and removes the need for environmental vorticity. Currently, the two methods of investigation are being combined to produce even more comprehensive results (Kost and Richardson 2004). It also is possible that the responses to shear variations would differ in a different low-level moisture [i.e., CAPE and convective inhibition (CIN)] regime, particularly in the weak shear cases where the amount of CIN likely has a strong influence on the ability of the cold pool lifting to initiate new storms.

Acknowledgments. This research was supported by the National Science Foundation under Grant ATM9222576, by a subcontract of Grant ATM-9981130 to The Pennsylvania State University, by Grant ATM9120009 to the Center for Analysis and Prediction of Storms, by the University of Oklahoma as a Centennial Research Assistantship and a Patricia Roberts Harris Fellowship, and by the University of Oklahoma School of Meteorology as part of a visiting faculty appointment. The numerical simulations were performed at the Pittsburgh Supercomputing Center, the San Diego Supercomputing Center, and the Environmental Computing Applications System at the University of Oklahoma. The latter is funded by the National Science Foundation under Grant EAR95-12145 and by the University of Oklahoma. Some of the graphics were generated using the ZXPLOT package developed by Ming Xue at the University of Oklahoma. We are grateful for helpful comments from Douglas Lilly, Fred Carr, Alan Shapiro, John Albert, and two anonymous reviewers. We also would like to thank Ming Xue for many helpful discussions.

\section{REFERENCES}

Atkins, N. T., M. L. Weisman, and L. J. Wicker, 1999: The influence of preexisting boundaries on supercell evolution. Mon. Wea. Rev., 127, 2910-2927.

Bryan, G. H., 2005: Spurious convective organization in simulated squall lines owing to moist absolutely unstable layers. Mon. Wea. Rev., 133, 1978-1997.

_ J. C. Wyngaard, and J. M. Fritsch, 2003: Resolution requirements for the simulation of deep moist convection. Mon. Wea. Rev., 131, 2394-2416.

Burgess, D. W., and E. B. Curran, 1985: The relationship of storm type to environment in Oklahoma on 26 April 1984. Preprints, 14th Conf. on Severe Local Storms, Indianapolis, IN, Amer. Meteor. Soc., 208-211.

Carpenter, K. M., 1982: Note on the paper "Radiation conditions for the lateral boundaries of limited-area numerical models" by M. J. Miller and A. J. Thorpe. Quart. J. Roy. Meteor. Soc., 108, 717-719.

Coniglio, M. C., and D. J. Stensrud, 2001: Simulation of a progressive derecho using composite initial conditions. Mon. Wea. Rev., 129, 1593-1616.

Crook, N. A., and M. W. Moncrieff, 1988: The effect of large-scale convergence on the generation and maintenance of deep moist convection. J. Atmos. Sci., 45, 3606-3624.

Davies-Jones, R., 1984: Streamwise vorticity: The origin of updraft rotation in supercell storms. J. Atmos. Sci., 41, 29913006.

Deardorff, J. W., 1980: Stratocumulus-capped mixed layers derived from a three-dimensional model. Bound.-Layer Meteor., 18, 495-527.

Droegemeier, K. K., 1997: The numerical prediction of thunderstorms: Challenges, potential benefits, and results from realtime operational tests. WMO Bull., 46, 324-336.

Evans, J. S., and C. A. Doswell III, 2001: Examination of derecho environments using proximity soundings. Wea. Forecasting, 16, 329-342.

Johns, R. H., and W. D. Hirt, 1987: Derechos: Widespread convectively induced windstorms. Wea. Forecasting, 2, 32-49.

Kay, M. P., and L. J. Wicker, 1998: Numerical simulations of supercell interactions with thermal boundaries. Preprints, 19 th Conf. on Severe Local Storms, Minneapolis, MN, Amer. Meteor. Soc., 246-248.

Klemp, J. B., and R. B. Wilhelmson, 1978a: The simulation of 
three-dimensional convective storm dynamics. J. Atmos. Sci., 35, 1070-1096.

— , and — 1978b: The simulation of right- and left-moving storms produced through storm splitting. J. Atmos. Sci., 35, 1097-1110.

Kost, J., and Y. P. Richardson, 2004: The influence of temporallyvarying vertical wind shear on numerically simulated convective storms. Preprints, $22 d$ Conf. on Severe Local Storms, Hyannis, MA, Amer. Meteor. Soc., CD-ROM, 9.2.

Kron, J., 2004: The evolution of numerically-modeled convection in an environment containing horizontal variations of vertical shear and low-level moisture. M.S. thesis, Dept. of Meteorology, The Pennsylvania State University, $170 \mathrm{pp}$.

Lilly, D. K., 1986a: The structure, energetics and propagation of rotating convective storms. Part I: Energy exchange with the mean flow. J. Atmos. Sci., 43, 113-125.

, 1986b: The structure, energetics and propagation of rotating convective storms. Part II: Helicity and storm stabilization. $J$. Atmos. Sci., 43, 126-140.

Markowski, P. M., and Y.P. Richardson, 2007: Observations of vertical wind shear heterogeneity in convective boundary layers. Mon. Wea. Rev., 135, 843-861.

_ J. J. M. Straka, E. N. Rasmussen, and D. O. Blanchard, 1998: Variability of storm-relative helicity during VORTEX. Mon. Wea. Rev., 126, 2959-2971.

- C. Hannon, J. Frame, E. Lancaster, A. Pietrycha, R. Edwards, and R. L. Thompson, 2003: Characteristics of vertical wind profiles near supercells obtained from the Rapid Update Cycle. Wea. Forecasting, 18, 1262-1272.

Marwitz, J. D., 1972a: The structure and motion of severe hailstorms. Part I: Supercell storms. J. Appl. Meteor., 11, 166-179. , 1972b: The structure and motion of severe hailstorms. Part II: Multicell storms. J. Appl. Meteor., 11, 180-188.

_ 1972c: The structure and motion of severe hailstorms. Part III: Severely sheared storms. J. Appl. Meteor., 11, 189-201.

McCaul, E. W., and M. L. Weisman, 2001: The sensitivity of simulated supercell structure and intensity to variations in the shapes of environmental buoyancy and shear profiles. Mon. Wea. Rev., 129, 664-687.

Moeng, C. H., 1984: A large-eddy simulation model for the study of planetary boundary-layer turbulence. J. Atmos. Sci., 41, 2052-2062.

—, and J. C. Wyngaard, 1988: Spectral analysis of large-eddy simulations of the convective boundary layer. J. Atmos. Sci., 45, 3573-3587.

Moncrieff, M. W., and J. S. A. Green, 1972: The propagation and transfer properties of steady convective-overturning in shear. Quart. J. Roy. Meteor. Soc., 98, 336-352.

Rasmussen, E. N., and D. O. Blanchard, 1998: A baseline climatology of sounding-derived supercell and tornado forecast parameters. Wea. Forecasting, 13, 1148-1164.

Richardson, Y. P., 1999: The influence of horizontal variations in vertical shear and low-level moisture on numerically simu- lated convective storms. Ph.D. dissertation, School of Meteorology, University of Oklahoma, $236 \mathrm{pp}$.

Rotunno, R., and J. B. Klemp, 1982: The influence of the shearinduced pressure gradient on thunderstorm motion. Mon. Wea. Rev., 110, 136-151.

- and - 1985: On the rotation and propagation of simulated supercell thunderstorms. J. Atmos. Sci., 42, 271-292.

— - , and M. L. Weisman, 1988: A theory for strong, longlived squall lines. J. Atmos. Sci., 45, 463-485.

Skamarock, W. C., M. L. Weisman, C. A. Davis, and J. B. Klemp, 1994: The evolution of simulated mesoscale convective systems in idealized environments. Preprints, Sixth Conf. on Mesoscale Meteorology, Portland, OR, Amer. Meteor. Soc., 407-410.

Stensrud, D. J., M. C. Coniglio, R. P. Davies-Jones, and J. S. Evans, 2005: Comments on "A theory for strong long-lived squall lines' revisited.” J. Atmos. Sci., 62, 2989-2996.

Weisman, M. L., 1993: The genesis of severe, long-lived bow echoes. J. Atmos. Sci., 50, 645-670.

_ simulated convective storms on vertical wind shear and buoyancy. Mon. Wea. Rev., 110, 504-520.

- and - 1984: The structure and classification of numerically simulated convective storms in directionally varying wind shears. Mon. Wea. Rev., 112, 2479-2498.

— , and R. Rotunno, 2004: "A theory for strong long-lived squall lines" revisited. J. Atmos. Sci., 61, 361-382.

—, and —, 2005: Reply. J. Atmos. Sci., 62, 2997-3002.

_ J. B. Klemp, and R. Rotunno, 1988: Structure and evolution of numerically simulated squall lines. J. Atmos. Sci., 45, 19902013.

_, M. S. Gilmore, and L. J. Wicker, 1998: The impact of convective storms on their local environment: What is an appropriate ambient sounding? Preprints, 19th Conf. on Severe Local Storms, Minneapolis, MN, Amer. Meteor. Soc., 238-241.

Xue, M., V. Wong, A. Shapiro, and K. Brewster, 1995: ARPS version 4.0 user's guide. Center for Analysis and Prediction of Storms, University of Oklahoma, Norman, OK, $380 \mathrm{pp}$.

—, K. K. Droegemeier, and V. Wong, 2000: The Advanced Regional Prediction System (ARPS) - A multiscale nonhydrostatic atmospheric simulation and prediction tool. Part I: Model dynamics and verification. Meteor. Atmos. Phys., 75, 161-193.

— , and Coauthors, 2001: The Advanced Regional Prediction System (ARPS) - A multiscale nonhydrostatic atmospheric simulation and prediction tool. Part II: Model physics and applications. Meteor. Atmos. Phys., 76, 143-165.

_, D.-H. Wang, J.-D. Gao, K. Brewster, and K. K. Droegemeier, 2003: The Advanced Regional Prediction System (ARPS), storm-scale numerical weather prediction and data assimilation. Meteor. Atmos. Phys., 82, 139-170.

Zalesak, S. T., 1979: Fully multidimensional flux-corrected transport algorithms for fluids. J. Comput. Phys., 31, 335-362. 